\title{
De metales, minerales y yacimientos. Contribución al estudio de la metalurgia prehispánica en el extremo noroccidental de Argentina
}

\section{RESUMEN}

Durante tiempos prehispánicos tardíos (1000 DC en adelante), el extremo noroccidental de Argentina fue escenario de un intenso tráfico de bienes materiales. Entre los productos trasladados ocuparon un lugar muy importante los objetos metálicos y los minerales metalíferos. Con la finalidad de contribuir al estudio de este tema, en el presente artículo combinamos los resultados de una serie de análisis de composición efectuados sobre objetos metálicos hallados en la quebrada de Humahuaca (provincia de Jujuy) con información geológica sobre yacimientos y asociaciones minerales presentes en la región. Nuestros estudios nos sugieren que los metalurgos prehispánicos han procesado una gran variedad de minerales metalíferos para la fabricación de las piezas consideradas. Algunos de estos minerales (por ejemplo, varios de cobre) pudieron haber sido obtenidos en la misma quebrada, pero otros (como el oro y minerales de estaño) debieron ser trasladados desde grandes distancias. Este estudio constituye un primer paso para el diseño de estrategias para la detección de explotaciones mineras prehispánicas, rutas de tráfico de minerales y localización de lugares de procesamiento de las materias primas.

Palabras claves: metalurgia prehispánica - minerales metalíferos - yacimientos minerales - quebrada de Humahuaca.

\begin{abstract}
In late prehispanic times (from $1000 \mathrm{AD}$ on) an intense trade of goods took place in Northwest Argentina. These included metallic pieces and metalliferous minerals. In this paper we aim to contribute to the subject, through the combination of results of studies made on such pieces found in the quebrada de Humahuaca (Jujuy) and metallic geological information on regional mineral fields. Our research shows that prehispanic metallurgists processed a variety of metalliferous minerals in manufacturing the pieces. Some of those, as copper ores, could have been obtained locally, but others such as gold and tin, had to be brought from long distances. This research is the first step in designing strategies and techniques for detecting prehispanic mine working, mineral trade routes and location of sites where raw material processing was carried out.
\end{abstract}

Key words: prehispanic metallurgy - metalliferous minerals - mineral fields - quebrada de Humahuaca.

\section{Introducción}

Durante tiempos prehispánicos tardíos (1000 DC en adelante) la Subárea Circumpuneña ha sido escenario de un intenso tráfico de bienes materiales (Browman 1984; Nielsen 2000; Núñez y Dillehay 1995; Tarragó 1977, entre otros). Los objetos metálicos y los minerales metalíferos formaron parte importante del conjunto de elementos trasladados (Núñez 1987; Nielsen 1999 y 2001) y la quebrada de Humahuaca, un valle árido localizado en el sector central de la provincia de Jujuy, Argentina, ha participado regularmente de estas verdaderas redes de circulación de productos (Nielsen 1998). Con la finalidad de aportar al estudio de este tema, realizamos una serie de análisis de composición sobre piezas metálicas recuperadas en varios asentamientos de la quebrada. En este artículo combinamos los resultados de esos estudios con información geológica sobre yacimientos y asociaciones de minerales del extremo noroccidental de Argentina. Este representa un primer paso para el estudio de la circulación de productos vinculados con actividades metalúrgicas en la región.

La quebrada de Humahuaca constituyó una de las áreas del Noroeste Argentino en las que la producción de objetos metálicos alcanzó un mayor desarrollo. Nuestros estudios nos sugieren la existencia de un proceso de producción metalúrgica muy complejo, con personas que organizaban y controlaban, directa o indirectamente, el aprovisionamiento de minerales metalíferos, el trabajo de los metalurgos y la distribución de las piezas fabricadas. Hemos propuesto que grupos distintos (quebradeños y puneños) habrían participado en el mismo proceso de producción, que las tareas vinculadas con las diversas etapas producti-

\footnotetext{
1 Instituto de Arqueología y Museo, Universidad Nacional de Tucumán. Casilla de Correo 8. (4107) Yerba Buena, Tucumán, Argentina. Email: horcomolle@yahoo.com.ar
} 
vas se encontraban espacialmente segregadas, y que en los grandes asentamientos de la época existían talleres en los cuales se elaboraban objetos metálicos para consumo extradoméstico (Angiorama 1999 y $2001 \mathrm{Ms}$ ). En este trabajo exploramos un aspecto poco estudiado del proceso de producción metalúrgica en el área: la identificación de los posibles minerales procesados para la elaboración de piezas metálicas y la localización de sus probables fuentes.

\section{Los recursos minerales del área de estudio}

El proceso de producción metalúrgica comienza con la obtención de los minerales a partir de los cuales se extraerán los metales para la elaboración de los objetos. Los minerales son cuerpos naturales, sólidos, inorgánicos, de composición química homogénea, que normalmente se agrupan en cuerpos mayores: las rocas.

A diferencia del oro, que se encuentra generalmente en la naturaleza en estado casi puro, los demás metales suelen presentarse en diversas combinaciones. El cobre, por ejemplo, puede encontrarse como elemento nativo, como óxido y carbonato de cobre, tal como la malaquita, o como sulfuro de cobre, tal como la calcopirita. Es decir, un mismo metal puede obtenerse de diferentes minerales. El tipo de mineral es clave para reconstruir la tecnología metalúrgica prehispánica, porque los métodos utilizados para extraer un metal de un óxido o de un carbonato difieren de aquellos empleados para extraerlo de un sulfuro (González 1992).

En un mismo yacimiento pueden estar presentes uno solo o varios minerales de un mismo metal. En el caso del cobre, por ejemplo, podemos encontrar asociados en un mismo depósito malaquita, azurita y crisocola. De igual forma, de un único mineral puede obtenerse más de un metal: por ejemplo, la estannita proporciona cobre y estaño a la vez. Es decir, un único yacimiento puede ofrecer varios metales, a partir de uno o varios minerales.

Los yacimientos minerales adoptan tres formas básicas (tomado de González 1992):

a) los filones o vetas: son depósitos producidos por rellenos de fisuras o grietas preexistentes, y pueden presentar afloramientos. El mineral valioso se encuentra distribuido por todo el filón, pero heterogéneamente, conformando zonas ricas y pobres.

b) las capas o mantos: originadas por depósitos en el seno de agua, originalmente con una estratificación horizontal pero que, por movimientos de la corteza, frecuentemente se encuentran plegados. Tienen una mayor extensión horizontal que los filones y la potencia y distribución de la mineralización es más homogénea.

c) los bolsones, lentes o impregnaciones: son yacimientos irregulares caracterizados por depósitos minerales en localizaciones discretas.

Algunos metales, como por ejemplo el oro, pueden encontrarse también en depósitos secundarios originados generalmente por actividad fluvial: el agua erosiona algunos de los tipos de yacimientos descritos, transporta los minerales y los deposita en otro lugar.

Gracias a los análisis de composición efectuados, sabemos que los metalurgos prehispánicos de la quebrada de Humahuaca fabricaron objetos utilizando cobre, estaño, oro y plata. Afortunadamente la mineralogía de la región ha sido bien investigada, de manera que es posible especificar los minerales que podrían haber sido utilizados en tiempos prehispánicos para obtener dichos metales y determinar su distribución geográfica. Podemos también inferir los minerales probablemente procesados por los artesanos prehispánicos por la presencia y concentración de ciertos elementos diagnósticos en los objetos metálicos. A veces, incluso, es posible determinar de qué lugar extrajeron la materia prima, una vez circunscrita la distribución de un mineral particular.

Para dilucidar estas cuestiones comenzamos por sistematizar en tablas y mapas la información disponible en Hojas Geológicas, libros, revistas especializadas, informes y mapas publicados. ${ }^{2}$ No nos limitamos a la quebrada de Humahuaca, sino que registramos todos los yacimientos localiza-

2 Este apartado es el resultado del análisis de numerosos trabajos editados e inéditos y de entrevistas con geólogos que han trabajado en la zona de estudio. Parte de la información recopilada fue tomada de las siguientes fuentes: Ahfeld 1948, Ahfeld y Angelelli 1948, Angelelli 1984, Angelelli et al. 1983, Coira 1979, Hoskold 1889, Sgrosso 1943, Subsecretaría de Minería 1973, Turner 1978 y1982, y Vilela 1969. 
dos en la provincia de Jujuy y los sectores de la provincia de Salta que limitan con ella. Algunos de estos depósitos son minas explotadas en la actualidad o lo han sido en épocas recientes. Otros, en cambio, aparentemente no han sido trabajados en tiempos históricos.

Dado que las asociaciones de minerales en ambientes geológicos particulares pueden ser de enorme utilidad para resolver problemas de procedencia de materias primas, registramos todos los minerales identificados en cada uno de los yacimientos, y no sólo los que pudieron haber sido fuente de cobre, estaño, oro o plata. Probablemente, no todos los minerales presentes en algunos depósitos han sido publicados, ya sea por el tipo de prospección efectuada, o porque los geólogos estuvieran interesados sólo en los minerales económicamente importantes. Sin embargo, el valor de la información aquí recopilada reside en que documenta la presencia y las asociaciones de ciertos minerales que podrían haber servido como materia prima para los objetos metálicos fabricados y usados en tiempos prehispánicos.

El cobre, el metal más utilizado en el Noroeste Argentino prehispánico, es muy abundante en la región estudiada. Se lo encuentra conformando los tres tipos de yacimientos mencionados (vetas, mantos y bolsones), distribuidos por todos los ambientes de la región: puna, cordillera oriental, quebradas, valles y sierras subandinas (Figura 1). En ocasiones se presenta en su estado nativo, pero normalmente lo hace conformando diversos minerales, de los cuales los más frecuentes son calcopirita, bornita y calcosina (sulfuros), malaquita y azurita (carbonatos), y crisocola (silicato) (Tabla 1).

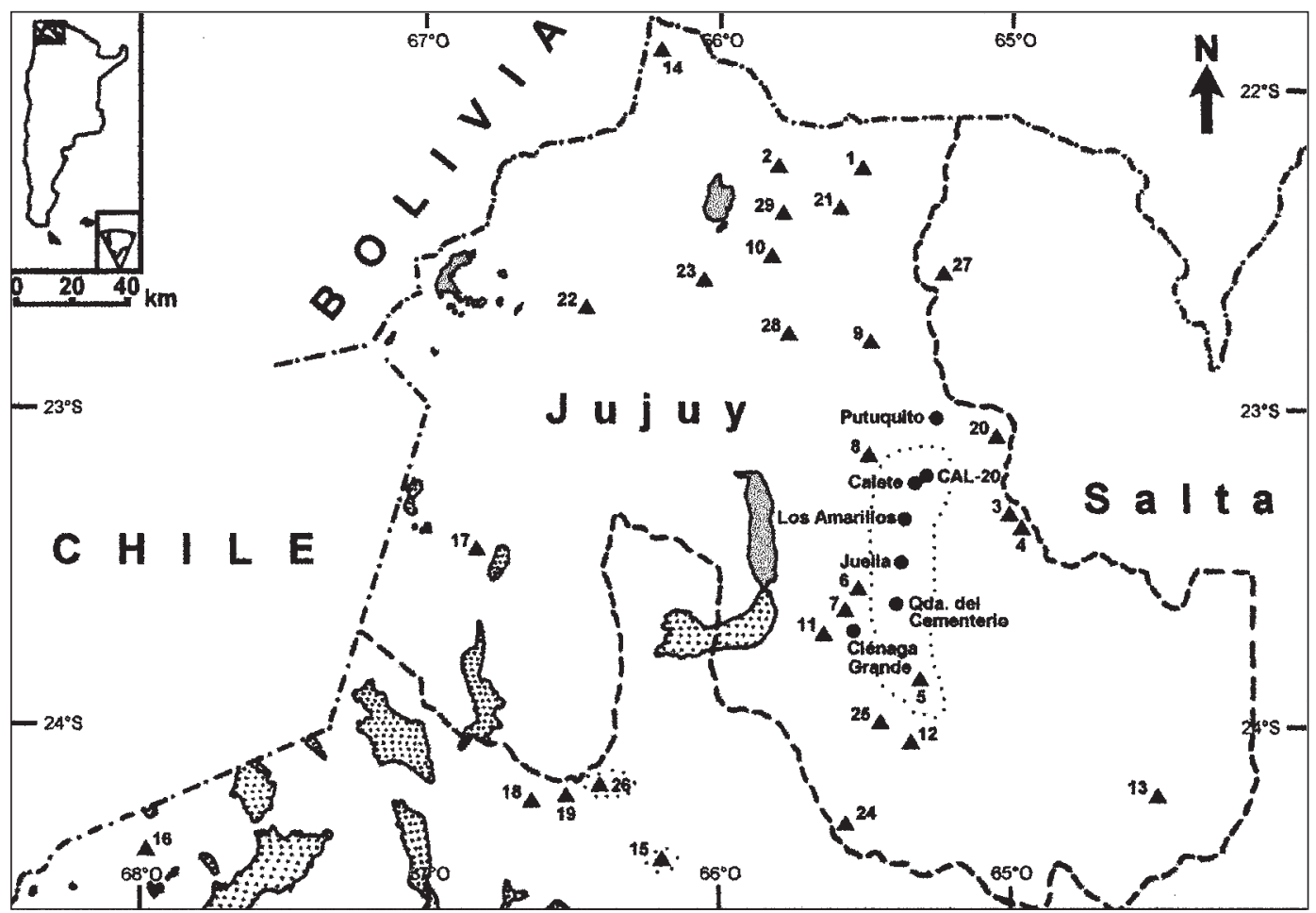

Laguna $\because$ Salar S Sitio arqueológico $\Delta$ Yacimiento de cobre

Area con yacimientos

Figura 1. Yacimientos de cobre.

Yacimientos: 1. Olga; 2. Cerro Escaya; 3. Santa Ana; 4. San Rafael; 5. Quebrada de Humahuaca; 6. Quebrada de Huichaira; 7. Quebrada de Hornillos; 8. Quebrada de Los Toldos; 9. Purísima; 10. Barcosconte; 11. Quebrada de Huachichocana; 12. Chorrillos; 13. Martín Bronce; 14. Eureka; 15. Maciso de Acay; 16. Taca Taca; 17. La Providencia; 18. El Quevar; 19. La Poma (ex-La Esperanza); 20. Palca de Aparzo; 21. Pumahuasi; 22. Pircas; 23. Pan de Azúcar; 24. Cerro Purma; 25. La Italiana; 26. Area Minera Concordia; 27. Quebrada Toroyoc; 28. La Candelaria; 29. La Sanguinaria. 
CARLOS I. ANGIORAMA

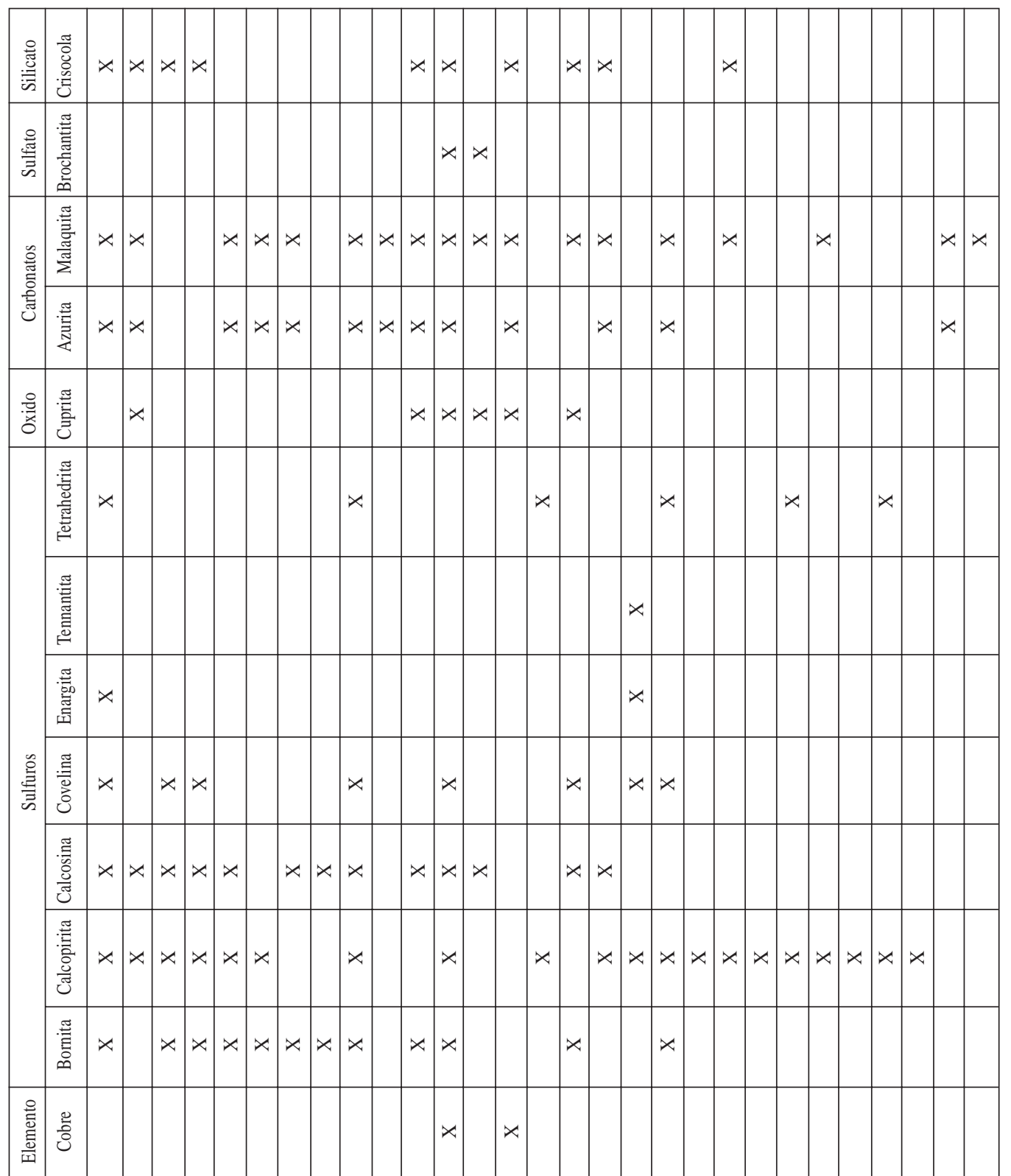

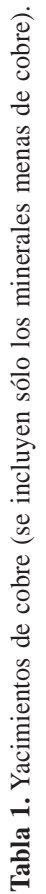

产

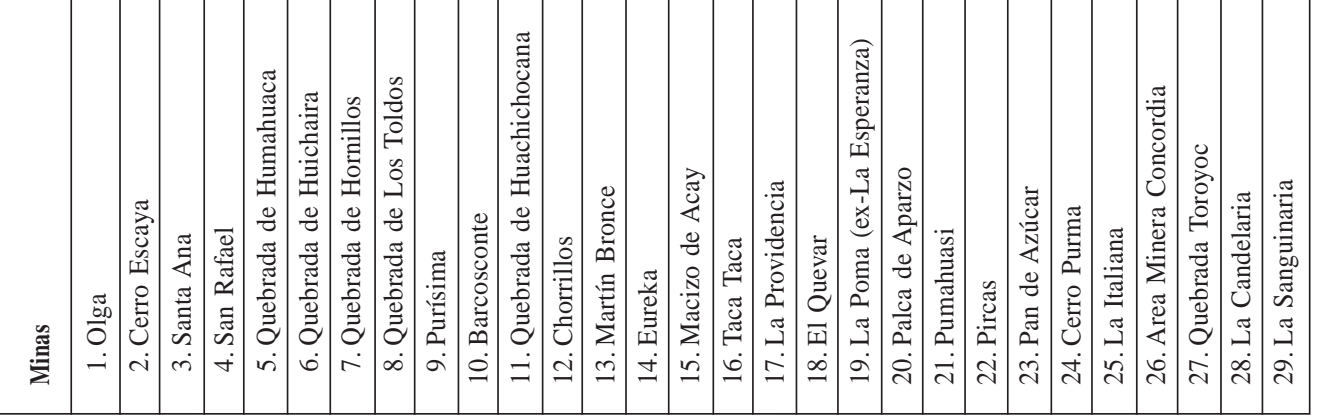


En la quebrada de Humahuaca y sus tributarias son comunes los bolsones de poco volumen con bornita como componente principal y calcosina y malaquita como minerales abundantes (Angelelli 1984). Estos bolsones se ubican a lo largo de toda la quebrada y a ambos márgenes, pero son especialmente frecuentes frente a las localidades de Humahuaca, Huacalera, Tilcara, Maimará y Purmamarca.

El estaño es relativamente abundante en la región estudiada, pero sus yacimientos se encuentran confinados al ambiente puneño (Figura 2). El yacimiento más cercano a la quebrada de Humahuaca en el que ha sido identificado es el de Pan de Azúcar, distante de ella unos $90 \mathrm{~km}$ en línea recta. Sin embargo, el estaño es sumamente escaso allí (Dr. Juan Avila, com. pers.), por lo que las principales fuentes se encuentran aún más alejadas. El estaño se presenta como casiterita (óxido), estannita y hexaestannita (sulfuros), siendo el primero el mineral más frecuente (Tabla 2). Sus manifestaciones principales consisten en depósitos vetiformes, generalmente muy pequeños, y grandes acumulaciones aluvionales, producto de la erosión de los primeros.

El oro también es un elemento relativamente abundante en la región estudiada. Los yacimientos auríferos son muy numerosos, aunque se limitan casi exclusivamente al ámbito puneño (Figura 3). Los depósitos son de dos tipos: vetiformes y, sobre todo, grandes concentraciones aluvionales. El oro se presenta principalmente como metal nativo, pero en algunos yacimientos existen pirita, arsenopirita y antimonita auríferas (sulfuros) (Tabla 3). En el ámbito quebradeño no se han detectado yacimientos de este metal. Los más cercanos son Chorrillos, Purísima y Sierra de Aguilar, distantes de la quebrada unos $35 \mathrm{~km}$ en línea recta. Sin embargo, en estos tres depósitos el oro es sumamente escaso.

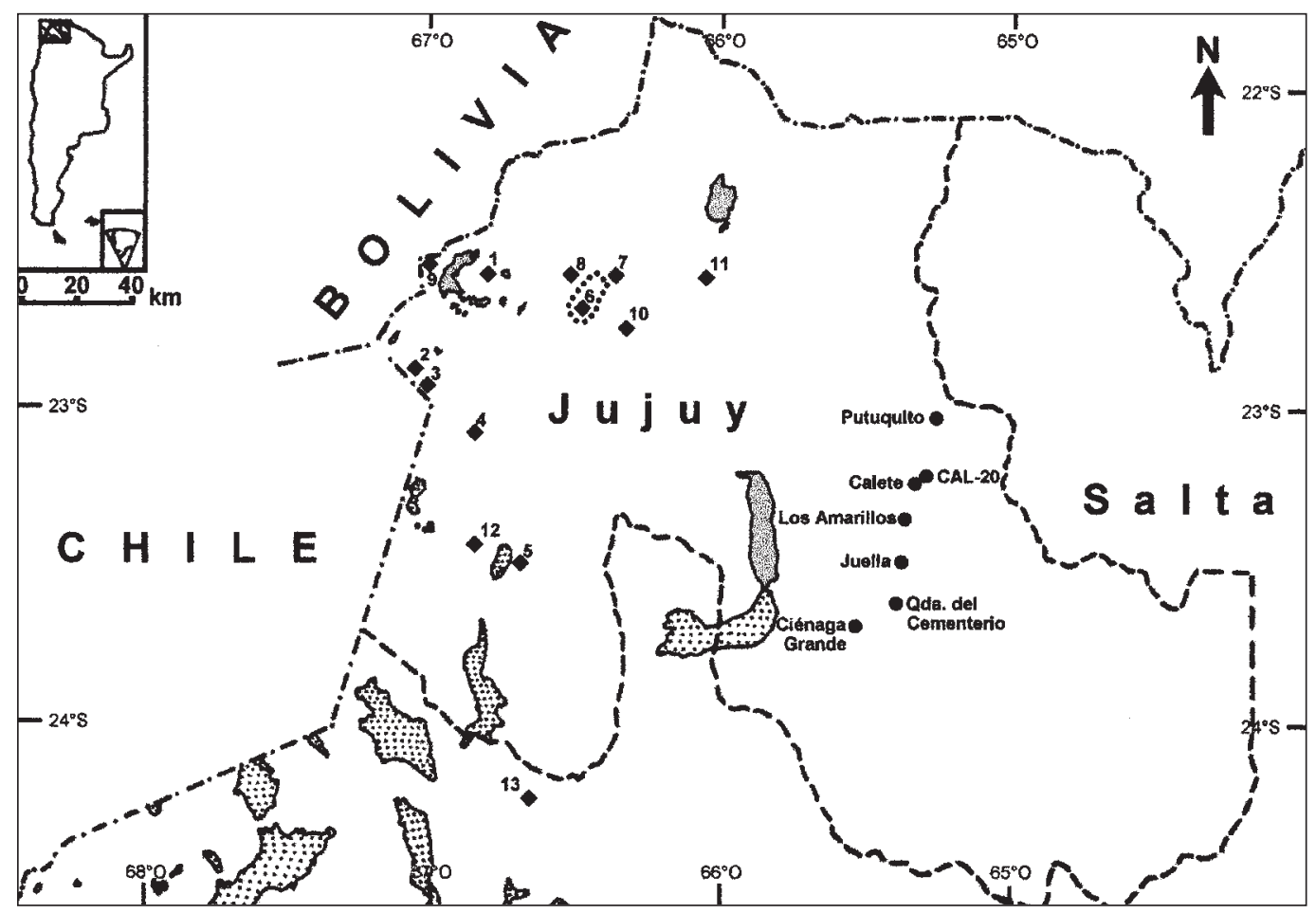

Laguna $\because$ Salar - Sitio arqueológico $\bullet$ Yacimiento de estaño

Figura 2. Yacimientos de estaño.

Yacimientos: 1. Cerro Pululus; 2. Sierra de Zapalieri; 3. Cerro San Pedro; 4. Cerro Pairique; 5. Cerro Yungara; 6. Pirquitas - San Marcos; 7. Orosmayo; 8. Cerro Caucani; 9. Cerro Negro; 10. Ajedrez; 11. Pan de Azúcar; 12. La Providencia; 13. El Quevar. 


\begin{tabular}{|c|c|c|c|}
\hline \multirow[b]{2}{*}{ Minas } & \multicolumn{2}{|c|}{ Sulfuros } & \multirow{2}{*}{$\begin{array}{c}\text { Oxido } \\
\text { Casiterita }\end{array}$} \\
\hline & Estannita & Hexaestannita & \\
\hline 1. Cerro Pululus & & & $\mathrm{X}$ \\
\hline 2. Sierra de Zapalieri & & & $\mathrm{X}$ \\
\hline 3. Cerro San Pedro & & & $\mathrm{X}$ \\
\hline 4. Cerro Pairique & & & $\mathrm{X}$ \\
\hline 5. Cerro Yungara & & & $\mathrm{X}$ \\
\hline 6. Pirquitas - San Marcos & $\mathrm{X}$ & & $\mathrm{X}$ \\
\hline 7. Orosmayo & & & $\mathrm{X}$ \\
\hline 8. $\quad$ Cerro Caucani & & & $\mathrm{X}$ \\
\hline 9. Cerro Negro & & & $\mathrm{X}$ \\
\hline 10. Ajedrez & & & $\mathrm{X}$ \\
\hline 11. Pan de Azúcar & $\mathrm{X}$ & $\mathrm{X}$ & $\mathrm{X}$ \\
\hline 12. La Providencia & $\mathrm{X}$ & & \\
\hline 13. El Quevar & $\mathrm{X}$ & $\mathrm{X}$ & $\mathrm{X}$ \\
\hline
\end{tabular}

Tabla 2. Yacimientos de estaño (se incluyen sólo los minerales menas de estaño).
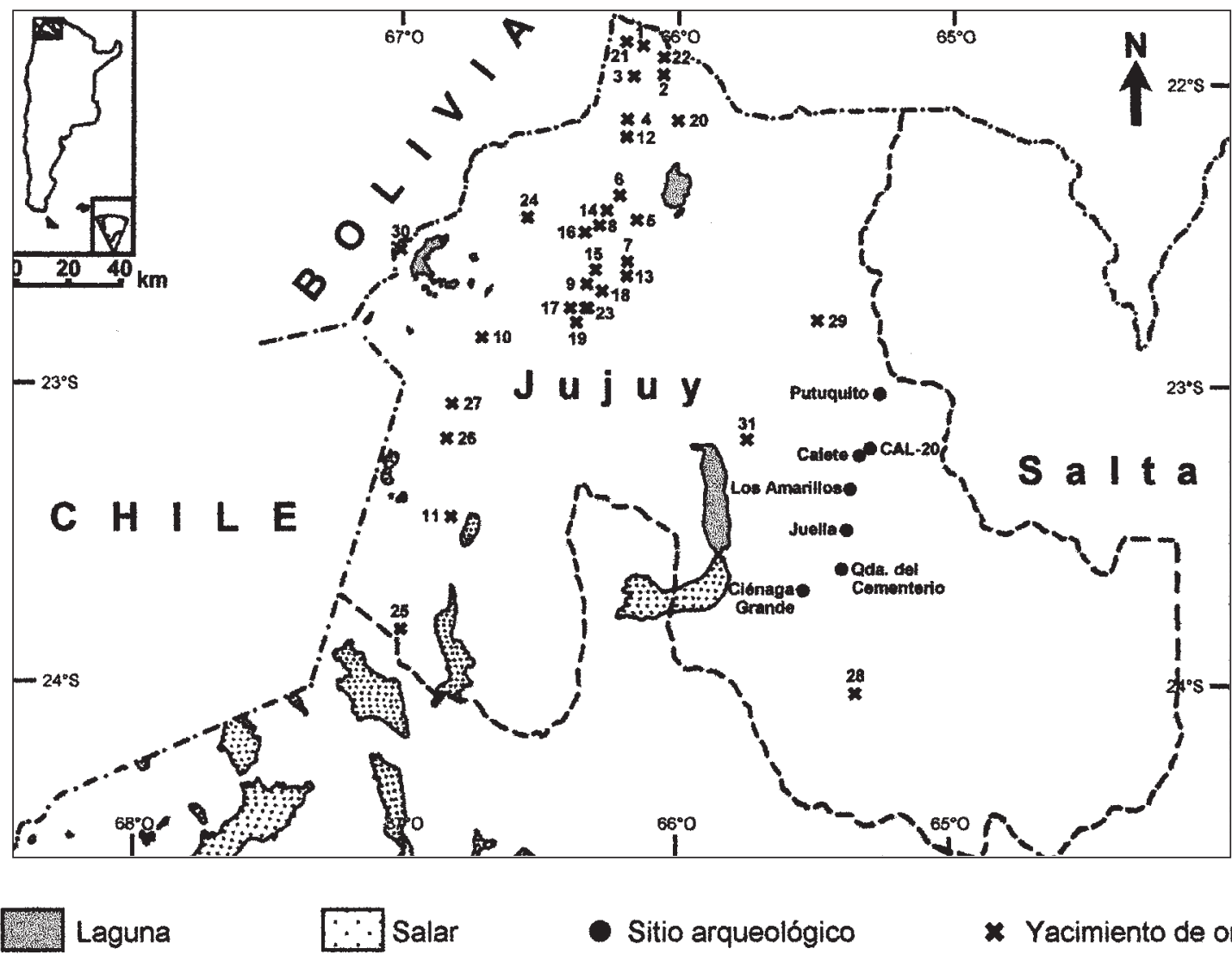

Figura 3. Yacimientos de oro.

Yacimientos: 1. El Torno o La Perdida; 2. Azules; 3. San Francisco; 4. Pucará Chico; 5. Rinconada; 6. San José de Rinconada; 7. Santo Domingo; 8. El Carmen; 9. Farillón; 10. Rosario de Coyahuaima; 11. La Providencia; 12. Timón Cruz; 13. Nazareno; 14. Alto del Carmen; 15. Chiricoya; 16. San Pedro; 17. Quebrada del Rancho Viejo; 18. Pampa Coya; 19. Antiguyoc; 20. El Cóndor; 21. Eureka; 22. Río Santa Catalina; 23. Ajedrez; 24. Pabellón; 25. Catúa; 26. El Toro; 27. Pairique; 28. Chorrillos; 29. Purísima; 30. Cerro Negro; 31. Sierra de Aguilar. 


\begin{tabular}{|c|c|c|c|c|c|}
\hline \multirow[b]{2}{*}{ Minas } & \multirow{2}{*}{ Minerales } & \multirow{2}{*}{$\begin{array}{c}\text { Elemento } \\
\text { Oro }\end{array}$} & \multicolumn{3}{|c|}{ Sulfuros } \\
\hline & & & Antimonita & Arsenopirita & Pirita \\
\hline 1. $\quad$ El Torno o La Perdida & & $\mathrm{X}$ & $X$ & & $\mathrm{X}$ \\
\hline 2. $\quad$ Azules & & $\mathrm{X}$ & & & \\
\hline 3. San Francisco & & $\mathrm{X}$ & $\mathrm{X}$ & $\mathrm{X}$ & $\mathrm{X}$ \\
\hline 4. $\quad$ Pucará Chico & & $\mathrm{X}$ & & & \\
\hline 5. $\quad$ Rinconada & & $\mathrm{X}$ & & $\mathrm{X}$ & $\mathrm{X}$ \\
\hline 6. San José de Rinconada & & $\mathrm{X}$ & & $\mathrm{X}$ & $\mathrm{X}$ \\
\hline 7. $\quad$ Santo Domingo & & $\mathrm{X}$ & & $\mathrm{X}$ & $\mathrm{X}$ \\
\hline 8. El Carmen & & $\mathrm{X}$ & & & \\
\hline 9. Farillón & & $\mathrm{X}$ & & & $\mathrm{X}$ \\
\hline 10. Rosario de Coyahuaima & & $\mathrm{X}$ & & & \\
\hline 11. La Providencia & & $\mathrm{X}$ & & & $\mathrm{X}$ \\
\hline 12. $\quad$ Timón Cruz & & $\mathrm{X}$ & & & \\
\hline 13. Nazareno & & $\mathrm{X}$ & & & \\
\hline 14. Alto del Carmen & & $\mathrm{X}$ & & & \\
\hline 15. Chiricoya & & $\mathrm{X}$ & & & \\
\hline 16. $\quad$ San Pedro & & $\mathrm{X}$ & & & \\
\hline 17. Quebrada del Rancho Viejo & & $\mathrm{X}$ & & & \\
\hline 18. $\quad$ Pampa Coya & & $\mathrm{X}$ & & & \\
\hline 19. $\quad$ Antiguyoc & & $\mathrm{X}$ & & & \\
\hline 20. El Cóndor & & $\mathrm{X}$ & & & \\
\hline 21. $\quad$ Eureka & & $\mathrm{X}$ & & & \\
\hline 22. Río Santa Catalina & & $\mathrm{X}$ & & & \\
\hline 23. $\quad$ Ajedrez & & $\mathrm{X}$ & & & \\
\hline 24. Pabellón & & $\mathrm{X}$ & $\mathrm{X}$ & & \\
\hline 25. Catúa & & $\mathrm{X}$ & & & \\
\hline 26. $\quad$ El Toro & & $\mathrm{X}$ & & & \\
\hline 27. Pairique & & $\mathrm{X}$ & & & \\
\hline 28. Chorrillos & & $X$ & & & $X$ \\
\hline 29. Purísima & & $\mathrm{X}$ & & & $\mathrm{X}$ \\
\hline 30. Cerro Negro & & $\mathrm{X}$ & & & \\
\hline 31. $\quad$ Sierra de Aguilar & & $\mathrm{X}$ & & $\mathrm{X}$ & $\mathrm{X}$ \\
\hline
\end{tabular}

Tabla 3. Yacimientos de oro (se incluyen sólo los minerales menas de oro).

La provincia de Jujuy es muy rica en plata. Los yacimientos, normalmente vetas y mantos, son muy numerosos y no se limitan al ámbito puneño, sino que están presentes también en la cordillera oriental y en las sierras subandinas (Figura 4). La plata se presenta principalmente como impureza en la galena (sulfuro), pero también son frecuentes otros minerales argentíferos, especialmente pirargirita, polibasina y argentita (sulfuros). La plata nativa, en cambio, es escasa en la región estudiada (Tabla 4). En la quebrada de Humahuaca no se han registrado yacimientos argentíferos, pero a pocos kilómetros de ella se encuentran varios depósitos como, por ejemplo, Cerro Chañi, Gigante, Palca de Aparzo, Sierra de Aguilar y La Italiana.

En resumen, los cuatro metales aparentemente utilizados por los metalurgos prehispánicos para la fabricación de objetos están presentes en cantidades importantes en la región estudiada. Sin embargo, el cobre es el único de ellos que puede obtenerse en el ámbito quebradeño, a los demás debe extraérselos de yacimientos localizados en otros ambientes (puna, cordillera oriental, sierras subandinas).

\section{Los objetos metálicos analizados}

Para dilucidar cuestiones tales como cuáles han sido los minerales procesados para la obtención de los metales y de cuáles de los yacimientos existentes se los pudo haber extraído, puede resultar clave conocer la composición de las piezas terminadas y de los residuos de fundición (escoria, gotas, recortes, etc.). Por tal motivo, recopilamos los datos ya publicados de composición de objetos prehispánicos de metal hallados en la quebrada de Humahuaca, productos de estudios efectuados por otros investigadores, y aportamos nuevos datos, resultados de nuestros propios análisis. 


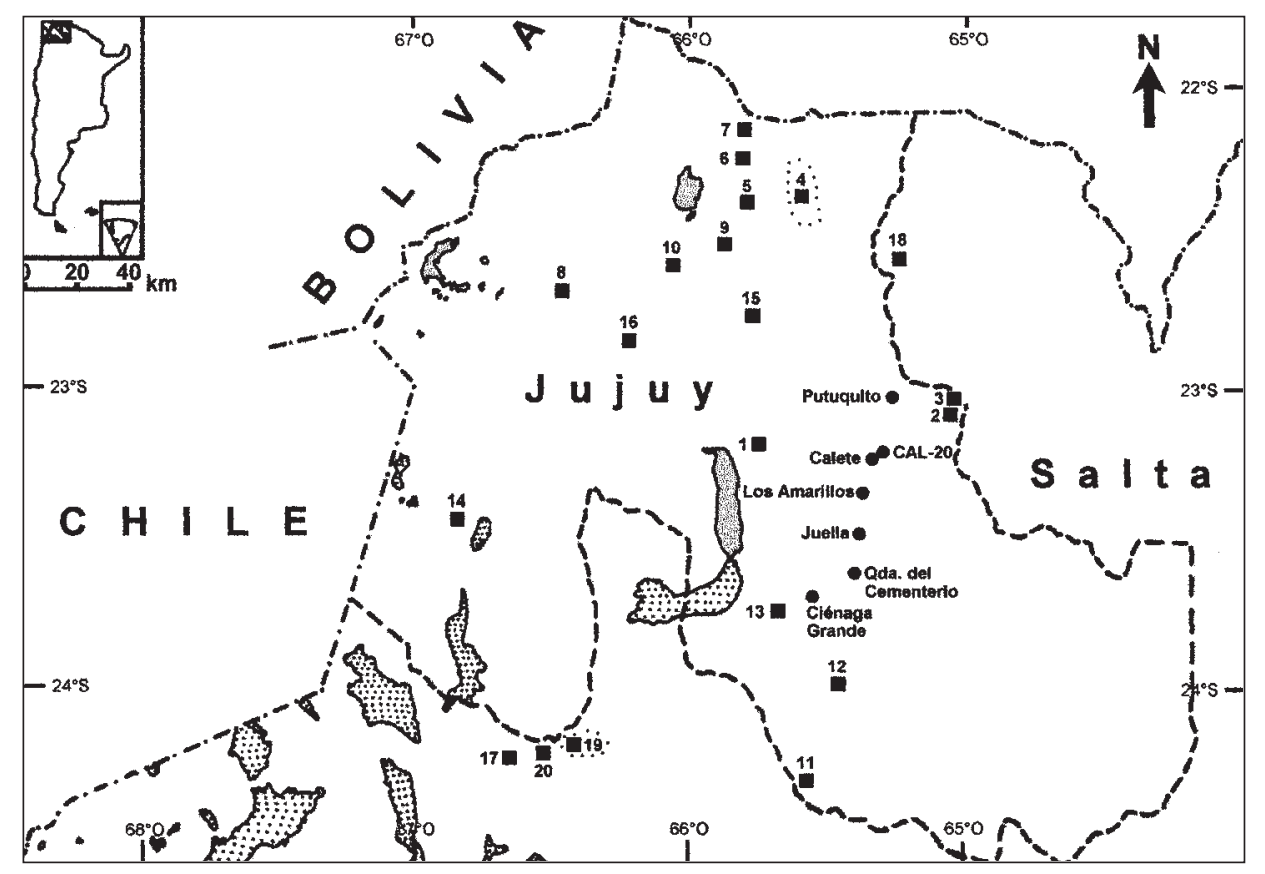

\section{Laguna $\because$ Salar Sitio arqueológico Yacimiento de plata}

Figura 4. Yacimientos de plata.

Yacimientos: 1. Sierra de Aguilar; 2. Palca de Aparzo; 3. Gigante; 4. Pumahuasi-Cangrejillos; 5. La Sanguinaria; 6. Cerro Escaya; 7. EscayaSierra de Cochinoca; 8. Pircas; 9. Chinchillas; 10. Pan de Azúcar; 11. Cerro Purma; 12. La Italiana; 13. Cerro Chañi; 14. La Providencia; 15. La Candelaria; 16. Rachaite; 17. El Quevar; 18. Quebrada Toroyoc; 19. Area Minera Concordia; 20. La Poma (ex La Esperanza).

\begin{tabular}{|c|c|c|c|c|c|c|c|}
\hline \multirow[t]{2}{*}{ Minerales } & \multirow{2}{*}{$\frac{\text { Elemento }}{\text { Plata }}$} & \multicolumn{5}{|c|}{ Sulfuros } & \multirow{2}{*}{$\begin{array}{c}\text { Halogenuro } \\
\text { Cerargirita }\end{array}$} \\
\hline & & Argentita & Freibergita & Galena & Pirargirita & Polibasina & \\
\hline 1. Sierra de Aguilar & & & $\mathrm{X}$ & $\mathrm{X}$ & $\mathrm{X}$ & & \\
\hline 2. Palca de Aparzo & & & & $\mathrm{X}$ & & & \\
\hline 3. Gigante & & & & $\mathrm{X}$ & & & \\
\hline 4. Pumahuasi - Cangrejillos & & & & $\mathrm{X}$ & & & \\
\hline Pumahuasi & & & & $\mathrm{X}$ & & & \\
\hline Sol de Mayo y Matadero & & & & $\mathrm{X}$ & & & \\
\hline Cerro Colorado & & & & $\mathrm{X}$ & & & \\
\hline Leman & & & & $\mathrm{X}$ & & & \\
\hline Bélgica & & & & $\mathrm{X}$ & & & \\
\hline Pulpera & & & & $\mathrm{X}$ & & & \\
\hline Cangrejillos & & & & $\mathrm{X}$ & & & \\
\hline 5. La Sanguinaria & & & & $\mathrm{X}$ & & & \\
\hline 6. Cerro Escaya & & & & $\mathrm{X}$ & & & \\
\hline 7. Escaya - Sierra de Cochinoca & & & & $\mathrm{X}$ & & & \\
\hline 8. Pircas & $\mathrm{X}$ & $\mathrm{X}$ & & $\mathrm{X}$ & $\mathrm{X}$ & $\mathrm{X}$ & $\mathrm{X}$ \\
\hline 9. Chinchillas & & & & $\mathrm{X}$ & & & \\
\hline 10. Pan de Azúcar & & & $\mathrm{X}$ & $\mathrm{X}$ & $X$ & & \\
\hline 11. Cerro Purma & & & & $\mathrm{X}$ & & & \\
\hline 12. La Italiana & & & & $\mathrm{X}$ & & & \\
\hline 13. Cerro Chañi & & & & $\mathrm{X}$ & & & \\
\hline 14. La Providencia & $\mathrm{X}$ & $\mathrm{X}$ & & $\mathrm{X}$ & & & $\mathrm{X}$ \\
\hline 15. La Candelaria & & & & $\mathrm{X}$ & & & \\
\hline 16. Rachaite & & & & $\mathrm{X}$ & & & \\
\hline 17. El Quevar & & & $\mathrm{X}$ & $\mathrm{X}$ & $\mathrm{X}$ & $\mathrm{X}$ & \\
\hline 18. Quebrada Toroyoc & & & & $\mathrm{X}$ & & & \\
\hline 19. Area Minera Concordia & & & $\mathrm{X}$ & $\mathrm{X}$ & $\mathrm{X}$ & & \\
\hline 20. La Poma (ex La Esperanza) & & & $\mathrm{X}$ & $\mathrm{X}$ & & & \\
\hline
\end{tabular}

Tabla 4. Yacimientos de plata (se incluyen sólo los minerales menas de plata). 
Del enorme conjunto de objetos metálicos y elementos vinculados con actividades de producción metalúrgica prehispánica hallados en la quebrada de Humahuaca, se han analizado y publicado las composiciones de 36 piezas, procedentes de tres asentamientos distintos. Para los fines de este trabajo, sin embargo, no consideraremos 15 de ellos: cinco por haber sido mezcladas las muestras y analizadas juntas (Salas 1945) y diez por haberse medido la concentración de sólo cuatro elementos de su estructura, de manera que desconocemos si otros elementos importantes para nuestro estudio están presentes o no en los objetos (Tarragó y González 1998).

Las piezas analizadas y publicadas que consideraremos en este trabajo son presentadas en la Tabla 5 .

Bajo la dirección del Dr. Axel Nielsen, desde 1992 se han llevado a cabo prospecciones sistemáticas y excavaciones en la quebrada troncal y en algunas de las tributarias. Gracias a estos trabajos, en algunos de los sitios estudiados se han hallado elementos vinculados con la producción de objetos de metal, tales como piezas terminadas, frag- mentos de moldes, escoria, gotas de fundición y minerales. De ellos escogimos 37 elementos metálicos y los analizamos para conocer su composición. La selección se efectuó de manera de contar con una muestra representativa del conjunto, teniendo en cuenta los diversos tipos de objetos, posibles funciones, contextos, cronología y metales utilizados. Los objetos son los presentados en la Tabla 6 y Figuras 5 y 6.

En la Tabla 7 presentamos la distribución temporal tentativa de todos los elementos metálicos analizados que consideraremos en este artículo.

\section{Las técnicas de análisis empleadas}

Existen varias técnicas para determinar la composición química de objetos metálicos. La elección de una en particular depende de la pregunta que uno quiera responder y del grado de alteración que pueda ocasionársele a la pieza. Algunas de estas técnicas permiten identificar los elementos presentes en la muestra (análisis cualitativos); otras, además, la concentración en la que éstos se encuentran (análisis cuantitativos). Como los primeros son más rápidos, menos costosos y no re-

\begin{tabular}{|clcccc|}
\hline $\mathbf{N}^{\mathbf{0}}$ & OBJETO & CODIGO & SITIO & PROCEDENCIA & FASE $^{3}$ \\
\hline 1 & Cincel & 32 & Juella & Habitación 7 & Pukara \\
2 & Cincel & 36 & Juella & Habitación 7 & Pukara \\
3 & Cuchillo semilunar & 90 & Huella & - & Pukara \\
4 & Gota & - & Juella & Hukara \\
5 & Punzón & 51 & Juella & Habitación 13 & Pukara \\
6 & Aguja & 65650 & Ciénaga Grande & Sepulcro 8 de la Vivienda 6 & Inka \\
7 & Campanilla & 65606 & Ciénaga Grande & - & Pukara / Inka \\
8 & Cincel & 65608 & Ciénaga Grande & - & Pukara / Inka \\
9 & Cincel & 65660 & Ciénaga Grande & - & Pukara / Inka \\
10 & Cuchillo & 65611 & Ciénaga Grande & - & Pukara / Inka \\
11 & Gota & 65613 & Ciénaga Grande & Pukara / Inka \\
12 & Hachuela & 65607 & Ciénaga Grande & Pukara / Inka \\
13 & Lámina & 65605 & Ciénaga Grande & Sepulcro de la Vivienda 17 \\
14 & Lámina & 65632 & Ciénaga Grande & Sepulcro de la Vivienda 17 & Pukara / Inka \\
15 & No identificado & 65601 & Ciénaga Grande & - & Pukara / Inka \\
16 & No identificado & 65602 & Ciénaga Grande & - & Pukara / Inka \\
17 & Placa & 65600 & Ciénaga Grande & Sepulcro de la Vivienda 17 & Pukara / Inka \\
18 & Placa & 65604 & Ciénaga Grande & Sepulcro de la Vivienda 17 & Pukara / Inka \\
19 & Tumi & 65603 & Ciénaga Grande & - & Pukara / Inka \\
20 & Tumi & 65609 & Ciénaga Grande & - & Pukara / Inka \\
21 & Tumi & 65610 & Ciénaga Grande & Pukara / Inka \\
\hline
\end{tabular}

Tabla 5. Objetos metálicos analizados y publicados por Salas (1945) y Cigliano (1967) que consideramos en este trabajo. La asignación temporal es nuestra. Fases: Calete (1100-1280 DC), Sarahuaico (1280-1350 DC), Pukara (1350-1430 DC), Inka (1430-1535 DC).

3 El marco cronológico que hemos adoptado es el propuesto por Nielsen (1997). 


\begin{tabular}{|c|c|c|c|c|c|}
\hline $\mathbf{N}^{\mathbf{o}}$ & ОВЈЕTO & CODIGO & SITIO & PROCEDENCIA & FASE $^{3}$ \\
\hline 22 & Cincel & $10 / 2$ & CAL 20 & Basurero 1 & Calete \\
\hline 23 & Tumi & $999 / 0$ & Juella & Superficie D & Pukara \\
\hline 24 & Tumi & $1 / 1$ & Calete & Superficie & Pukara / Inka \\
\hline 25 & Cincel & $40 / 15$ & Quebrada del Cementerio & Recinto 3 & Sarahuaico \\
\hline 26 & Tumi & $55 / 1$ & Quebrada del Cementerio & Recinto 4-5 & Sarahuaico \\
\hline 27 & Cincel & $6 / 3$ & Putuquito & Sondeo 2 & Inka \\
\hline 28 & Anillo & $731 / 1$ & Los Amarillos & Recinto $303 \mathrm{E}$ & Pukara \\
\hline 29 & Badajo & $619 / 1$ & Los Amarillos & Complejo A, Recinto 15 & Pukara \\
\hline 30 & Badajo & $337 / 1$ & Los Amarillos & Complejo A, Recinto 16 & Pukara \\
\hline 31 & Campana & $560 / 17$ & Los Amarillos & Recinto 301 & Pukara \\
\hline 32 & Campanilla & $758 / 11$ & Los Amarillos & Recinto 303 & Pukara \\
\hline 33 & Cincel & $295 / 1$ & Los Amarillos & Complejo A, Recinto $1 \mathrm{~b}$ & Pukara \\
\hline 34 & Cinta & $353 / 1$ & Los Amarillos & Complejo A, Recinto 16 & Pukara \\
\hline 35 & Cinta & $342 / 1$ & Los Amarillos & Complejo A, Recinto 16 & Pukara \\
\hline 36 & Gota & $12 / 0$ & Los Amarillos & Complejo A, Recinto 1 & Pukara / Inka \\
\hline 37 & Gota & $394 / 1$ & Los Amarillos & Complejo B, Recinto 22 & Pukara / Inka \\
\hline 38 & Gota & $762 / 28$ & Los Amarillos & Recinto 303 & Pukara \\
\hline 39 & Gota & $101 / 12$ & Los Amarillos & Complejo A, Recinto 6 & Pukara / Inka \\
\hline 40 & Gota & $97 / 12 \mathrm{a}$ & Los Amarillos & Complejo A, Recinto 6 & Pukara / Inka \\
\hline 41 & Gota & $97 / 12 b$ & Los Amarillos & Complejo A, Recinto 6 & Pukara / Inka \\
\hline 42 & Hacha & $483 / 13 a$ & Los Amarillos & Complejo A, Recinto 7 & Inka \\
\hline 43 & Lámina & 108/1a & Los Amarillos & Complejo A, Recinto 5 & Pukara \\
\hline 44 & Lámina & $108 / 1 b$ & Los Amarillos & Complejo A, Recinto 5 & Pukara \\
\hline 45 & Lámina & $450 / 1$ & Los Amarillos & Complejo B, Recinto 21 & Pukara \\
\hline 46 & Lámina & $386 / 66$ & Los Amarillos & Complejo A, Recinto 16 & Pukara \\
\hline 47 & Lámina & $134 / 5$ & Los Amarillos & - & Desconocida \\
\hline 48 & No identificado & $289 / 1$ & Los Amarillos & Complejo A, Recinto $1 \mathrm{~b}$ & Pukara \\
\hline 49 & No identificado & $426 / 0$ & Los Amarillos & Complejo A, Recinto 16 & Pukara \\
\hline 50 & No identificado & $115 / 1$ & Los Amarillos & Complejo A, Recinto 2 & Pukara / Inka \\
\hline 51 & No identificado & $703 / 3 a$ & Los Amarillos & Recinto 302 & Pukara \\
\hline 52 & No identificado & $703 / 3 b$ & Los Amarillos & Recinto 302 & Pukara \\
\hline 53 & No identificado & $205 / 2$ & Los Amarillos & Complejo A, Recinto 7 & Pukara / Inka \\
\hline 54 & No identificado & $502 / 0$ & Los Amarillos & Complejo B, Recinto 21 & Pukara \\
\hline 55 & Punzón & $207 / 3$ & Los Amarillos & Complejo B, Recinto 20 & Calete \\
\hline 56 & Punzón & $704 / 15$ & Los Amarillos & Recinto 302 & Pukara \\
\hline 57 & Punzón & $745 / 1$ & Los Amarillos & Recinto 304 & Pukara \\
\hline 58 & Tumi & $268 / 1$ & Los Amarillos & Complejo A, Recinto 9 & Pukara / Inka \\
\hline
\end{tabular}

Tabla 6. Objetos metálicos analizados. Fases: Calete (1100-1280 DC), Sarahuaico (1280-1350 DC), Pukara (1350-1430 DC), Inka (1430-1535 DC).

\begin{tabular}{|c|c|c|c|c|c|c|c|}
\hline \multirow[t]{2}{*}{ OBJETOS } & \multirow[t]{2}{*}{ CD } & \multicolumn{5}{|c|}{ FASES } & \multirow[t]{2}{*}{ Totales } \\
\hline & & $\overline{\text { CAL }}$ & SAR & PUK & PUK/INKA & $\overline{\text { INKA }}$ & \\
\hline Anillos & & & & 1 & & & 1 \\
\hline Badajos & & & & 2 & & & 2 \\
\hline Campanas & & & & 1 & & & 1 \\
\hline Campanillas & & & & 1 & 1 & & 2 \\
\hline Cintas & & & & 2 & & & 2 \\
\hline Láminas & 1 & & & 4 & 2 & & 7 \\
\hline Hachas & & & & & & 1 & 1 \\
\hline Placas & & & & & 2 & & 2 \\
\hline Tumis & & & 1 & 1 & 5 & & 7 \\
\hline Agujas & & & & & & 1 & 1 \\
\hline Cinceles & & 1 & 1 & 3 & 2 & 1 & 8 \\
\hline Cuchillos & & & & 1 & 1 & & 2 \\
\hline Hachuelas & & & & & 1 & & 1 \\
\hline Punzones & & 1 & & 3 & & & 4 \\
\hline No identif. & & & & 5 & 4 & & 9 \\
\hline Gotas & & & & 2 & 6 & & 8 \\
\hline Totales & 1 & 2 & 2 & 26 & 24 & 3 & 58 \\
\hline
\end{tabular}

Tabla 7. Distribución temporal tentativa de los elementos metálicos analizados, agrupados por tipos de objetos. CD: cronología desconocida. Fases: CAL: Calete (1100-1280 DC); SAR: Sarahuaico (1280-1350 DC); PUK: Pukara (1350-1430 DC); Inka (1430-1535 DC). 


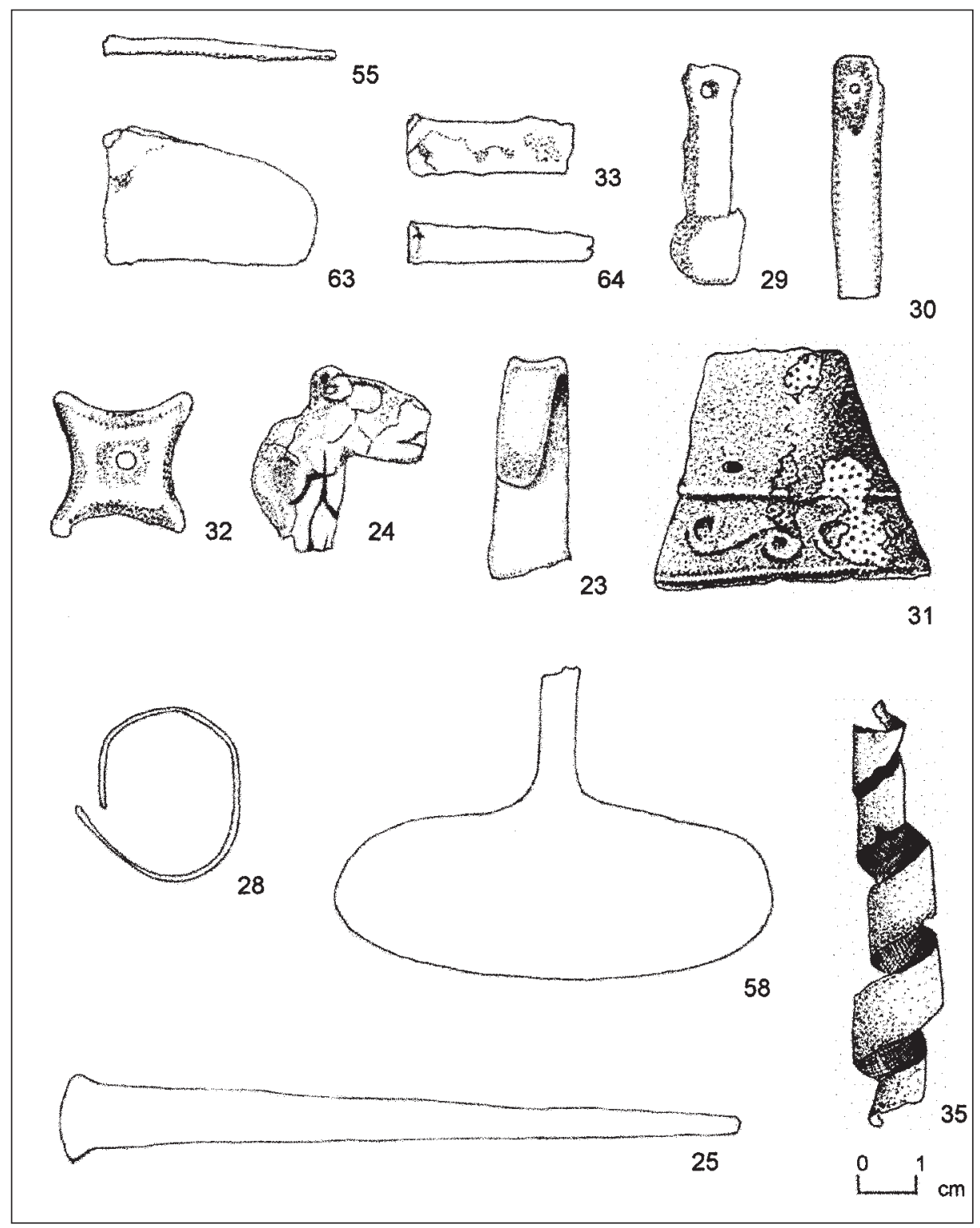

Figura 5. Objetos analizados (los números corresponden a los de la Tabla 6).

quieren de los objetos más que una superficie muy pequeña libre de pátina, una buena estrategia consiste en comenzar por ellos, para luego analizar mediante técnicas cuantitativas sólo aquellos artefactos cuyas composiciones proporcionales se deseen conocer por alguna razón.

Los resultados de estas técnicas no proveen una evidencia directa de los minerales fundidos para fabricar los objetos, pero sí permiten identificar los metales y aleaciones utilizados (Hosler 1994; Pernicka et al. 1997; Rovira Lloréns et al. 1998;
Tylecote 1970). Sobre la base de esa información, específicamente la presencia y concentración de ciertos elementos diagnósticos, y el conocimiento de la presencia, abundancia relativa y asociaciones de diversos minerales en la región de estudio, son posibles inferencias razonables sobre la materia prima probablemente empleada en tiempos prehispánicos.

Los análisis publicados que consideraremos en este trabajo son de tipo cuantitativo (o sea, conocemos las proporciones en que se encuentran cada 


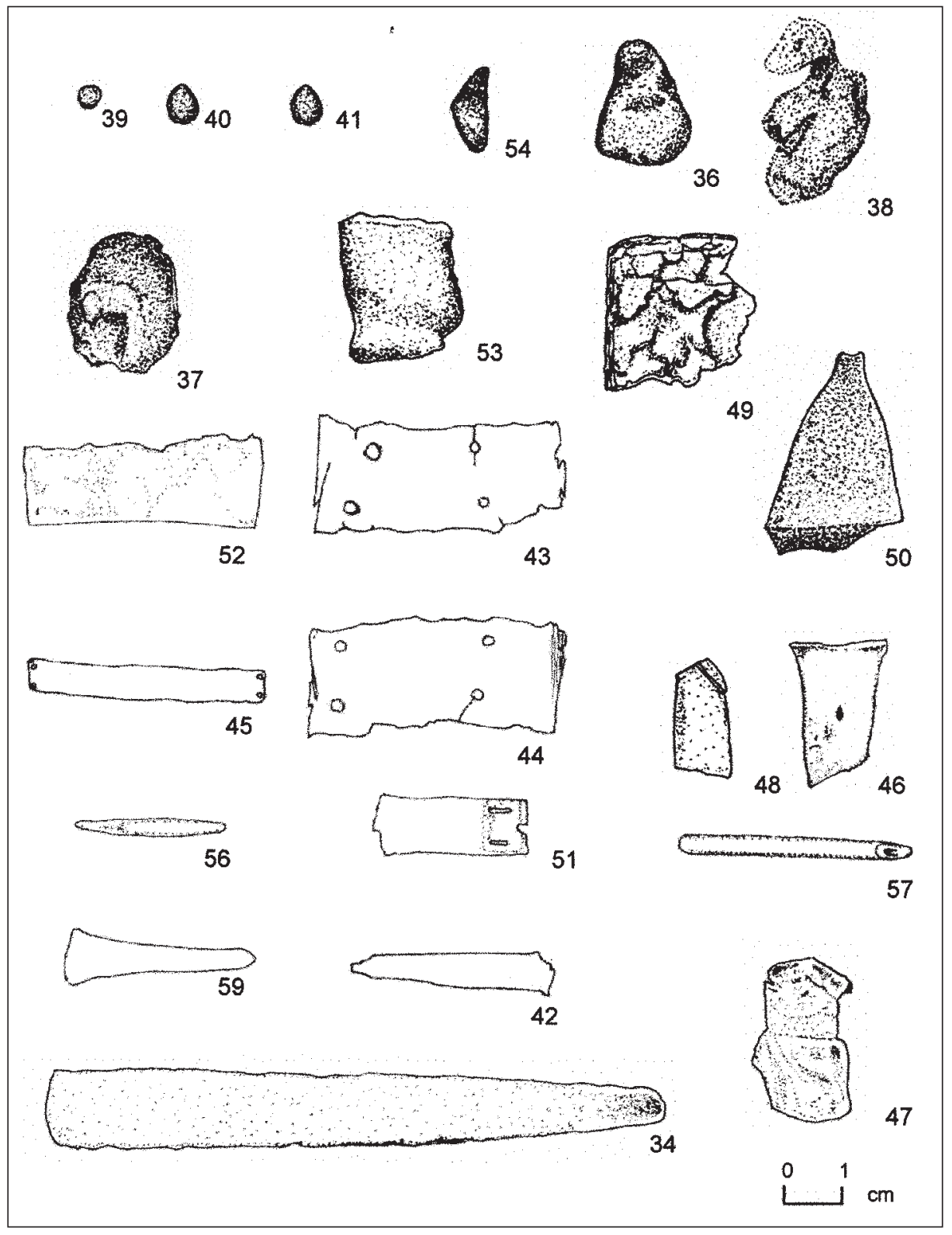

Figura 6. Objetos analizados (los números corresponden a los de la Tabla 6).

uno de los elementos que componen los objetos estudiados). Sin embargo, lamentablemente desconocemos las técnicas que fueron empleadas para la determinación de la composición de las piezas, ya que éstas no fueron especificadas en las publicaciones.

El problema que podrían presentar estos datos es que para la mayoría de las técnicas de análisis cuantitativo el investigador debe especificar de an- temano de cuáles de los elementos desea determinar su presencia o ausencia y su concentración. De esta manera, podría suceder que en algún objeto se hallara presente, incluso en gran cantidad, algún elemento no analizado. De todos modos, los seleccionados por Salas (1945) y Cigliano (1967) son relevantes para nuestro estudio e incluyen la gran mayoría de los elementos diagnósticos para el tipo de estudio que estamos presentando. 
Las mediciones efectuadas por nosotros, en cambio, son de tipo semicuantitativas (o sea, conocemos las concentraciones relativas de cada uno de los elementos que constituyen las piezas). Los análisis fueron efectuados mediante Dispersión de Energía de Rayos X (EDAX), ${ }^{4}$ empleándose un equipo Philips PSEM 500 acoplado a un Microscopio Electrónico de Barrido. De cada objeto se tomaron de tres a ocho mediciones en diversos sectores libres de pátina. En los casos que consideramos necesarios, se realizaron además determinaciones en la capa de corrosión para lograr un control eficaz de los resultados. En total se realizaron 140 mediciones.

Para diferencia de los análisis cuantitativos, el EDAX detecta en la muestra analizada todos los elementos de peso atómico mayor a 11 y que se encuentren en concentraciones de alrededor de un $1 \%$ o más, de manera que el investigador no debe seleccionar de antemano cuáles desea detectar.

Para los fines de nuestra investigación no existen inconvenientes en utilizar datos de técnicas de análisis de composición distintas. Lo que nos in- teresa en este trabajo es la presencia o no de cada elemento en la estructura de los objetos analizados y la concentración relativa de cada uno de los presentes. Tanto los publicados seleccionados como los derivados de los análisis por EDAX cumplen estos dos requisitos.

\section{Resultados de los análisis}

Basándonos en los resultados de los análisis podemos agrupar a los objetos en cuatro conjuntos (Gráfico 1):

a) el Grupo I, compuesto por piezas fabricadas sólo con cobre, a veces con otros metales presentes pero en cantidades muy pequeñas (trazas),

b) el Grupo II, integrado por artefactos elaborados con aleaciones de base cobre,

c) el Grupo III, compuesto por piezas confeccionadas con aleaciones de base oro, y

d) el Grupo IV, integrado por objetos fabricados con aleaciones de base plata.

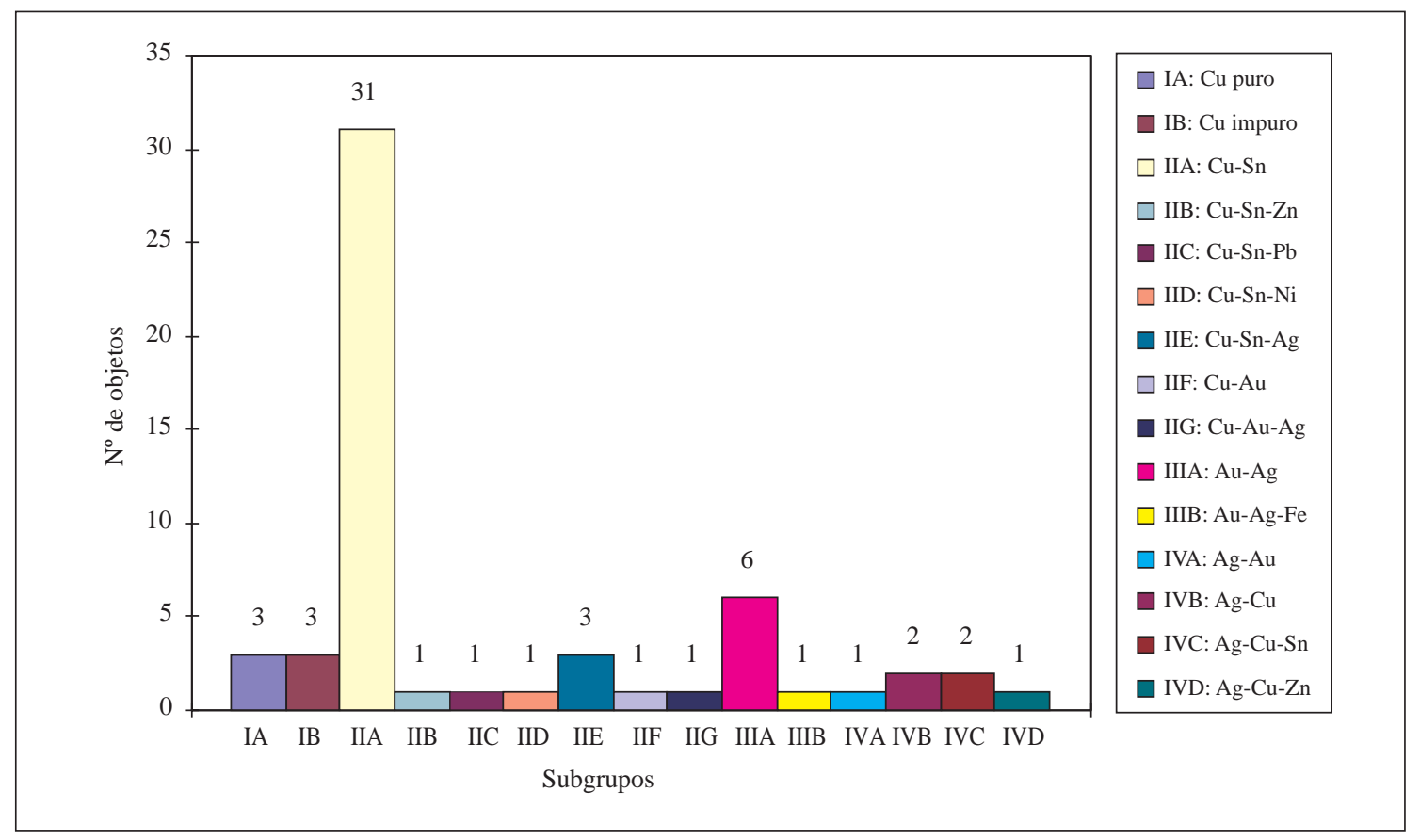

Gráfico 1. Subgrupos de composición.

\footnotetext{
4 Las mediciones fueron tomadas por Adriana Domínguez y Sara Novas en el Centro Atómico, constituyentes de la Comisión
} Nacional de Energía Atómica. 
Los objetos del Grupo I están elaborados con cobre, pero que deriva de fuentes distintas: cobre nativo o minerales secundarios de cobre muy puros (Subgrupo IA), y minerales primarios de cobre impuros (Subgrupo IB). El Grupo II consiste en objetos elaborados con aleaciones de base cobre: cobre-estaño (Subgrupo IIA), cobre-estañozinc (Subgrupo IIB), cobre-estaño-plomo (Subgrupo IIC), cobre-estaño-níquel (Subgrupo IID), cobre-estaño-plata (Subgrupo IIE), cobre-oro (Subgrupo IIF), y cobre-oro-plata (Subgrupo IIG). El Grupo III presenta piezas confeccionadas con aleaciones de base oro: oro-plata (Subgrupo IIIA), y oro-plata-hierro (Subgrupo IIIB). El Grupo IV está compuesto por objetos de aleaciones de base plata: plata-oro (Subgrupo IVA), plata-cobre (Subgrupo IVB), plata-cobre-estaño (Subgrupo IVC), plata-cobre-zinc (Subgrupo IVD).

En teoría, cada una de las diversas composiciones pudo haberse logrado de varias maneras. Teniendo en cuenta los minerales disponibles en la zona de estudio y la composición química de los artefactos, ¿cuáles de esas alternativas son las más probables en estos casos? A continuación proponemos algunas interpretaciones tentativas.

\section{Interpretación de los resultados}

\section{Grupo I}

El Grupo I está compuesto por seis objetos; tres de ellos, los que no contienen estaño, integran el Subgrupo IA, mientras que los tres restantes, que sí contienen estaño, constituyen el Subgrupo IB.

Subgrupo IA: cobre puro. De los tres artefactos que conforman el Subgrupo IA (Tabla 8), dos (las gotas de fundición) han sido logradas probablemente con cobre obtenido a partir de su estado nativo. ${ }^{5}$ El restante, en cambio, contiene en su composición trazas de hierro. La presencia de este elemento es muy común en minerales secundarios de cobre, tales como óxidos, carbonatos, sulfatos y silicatos (Maddin et al. 1980; Hosler 1994). Probablemente este último objeto (una campanilla), ha sido elaborado con metal obtenido de

5 Hemos previsto realizar estudios metalográficos para comprobar si las gotas poseen la microestructura característica de los elementos elaborados con cobre obtenido a partir de su estado nativo. alguno de estos minerales secundarios, relativamente puro. Los más comunes en la región de estudio son malaquita, azurita, crisocola y cuprita.

La existencia de aluminio, calcio, cloro y silicio en estas y todas las piezas presentadas más abajo fue detectada en la capa de corrosión. Su presencia se explica por el contacto del objeto con el sedimento que lo contenía.

Subgrupo IB: cobre impuro. Los análisis cualitativos revelaron que, a diferencia de los objetos anteriores, el badajo contiene trazas de estaño en su composición (Tabla 9). Este elemento es sumamente escaso en minerales secundarios de cobre, de manera que, siguiendo a Hosler (1994), el metal utilizado en su fabricación fue obtenido probablemente a partir de calcopirita, un sulfuro de cobre muy difundido, presente en casi todos los yacimientos cupríferos de la región.

Para las dos piezas cuya composición cuantitativa conocemos caben las mismas consideraciones (Tabla 10). Es más, la presencia de hierro en uno de ellos aumenta la probabilidad de que el metal haya sido obtenido a partir de calcopirita.

\section{Grupo II}

Este grupo está compuesto por 39 objetos, todos fabricados con aleaciones de base cobre. El Subgrupo más numeroso es el IIA, con 31 elementos elaborados con cobre-estaño. De los ocho restantes, uno compone el Subgrupo IIB (aleación cobre-zinc), otro el IIC (cobre-estaño-plomo), otro el IID (cobre-estaño-níquel), tres el IIE (cobreestaño-plata), uno el IIF (cobre-oro) y uno el IIG (cobre-oro-plata).

Subgrupo IIA: $\mathrm{Cu}$-Sn. Los objetos que integran el Subgrupo IIA presentados en la Tabla 11, pueden haber sido fabricados con una aleación obtenida directamente mediante la fundición de estannita, un sulfuro de cobre que contiene hierro y estaño. Este mineral se encuentra en algunos yacimientos de la región de estudio, aunque no es muy abundante. Sin embargo, según Petersen (1970), la estannita podría ser la causa de la presencia de estaño en concentraciones de hasta un $1.5 \%$ en peso, pero no más. Hasta que no dispongamos de los resultados de los análisis cuantitativos no podremos avanzar en este aspecto. De todas maneras, es más probable que la aleación haya sido 


\begin{tabular}{|c|c|c|c|c|c|c|c|c|c|c|}
\hline $\mathbf{N}^{0}$ & OВJETO & SITIO & RECINTO & CODIGO & $\mathrm{Cu}$ & $\mathrm{Fe}$ & Al & $\mathrm{Ca}$ & $\mathrm{Cl}$ & $\mathrm{Si}$ \\
\hline 32 & Campanilla & Los Amarillos & 303 & $758 / 11$ & ++ & - & + & - & - & - \\
\hline 38 & Gota & Los Amarillos & 303 & $762 / 28$ & ++ & & - & & - & - \\
\hline 41 & Gota & Los Amarillos & 6 & $97 / 12 b$ & ++ & & - & & - & - \\
\hline
\end{tabular}

Tabla 8. Piezas integrantes del Subgrupo IA (++: elemento base, +: elemento secundario, -: trazas).

\begin{tabular}{|cccccccc|}
\hline $\mathbf{N}^{\mathbf{0}}$ & OBJETO & SITIO & RECINTO & CODIGO & Cu & Sn & Al \\
\hline 30 & Badajo & Los Amarillos & 16 & $337 / 1$ & ++ & - & - \\
\hline
\end{tabular}

Tabla 9. Objeto integrante del Subgrupo IB (++: elemento base, -: trazas).

\begin{tabular}{|rccccccccccc|}
\hline $\mathbf{N}^{\mathbf{0}}$ & OBJETO & SITIO & CODIGO & $\mathbf{C u}$ & Sn & Pb & Ag & Au & Fe & $\mathbf{Z n}$ & $\mathbf{N i}$ \\
\hline 4 & Gota & Juella & - & 88.40 & 0.28 & $*$ & - & - & nd & nd & - \\
20 & Tumi & Cga. Gde. & 65609 & 95.30 & 0.61 & 0.32 & nd & nd & 1.85 & nd & nd \\
\hline
\end{tabular}

Tabla 10. Objetos integrantes del Subgrupo IB. Los valores expresan \% en peso. Referencias: nd: no detectado, *: no dosable con la técnica empleada, -: no analizado.

\begin{tabular}{|c|c|c|c|c|c|c|c|c|c|c|c|c|c|c|c|c|c|}
\hline $\mathbf{N}^{\mathbf{o}}$ & ОВЈЕТО & SITIO & RECINTO & CODIGO & $\mathrm{Cu}$ & Sn & $\mathrm{Au}$ & $\mathrm{Fe}$ & Co & $\mathbf{S}$ & Al & $\mathbf{K}$ & $\mathrm{Ca}$ & $\mathrm{Cl}$ & Mg & $\mathbf{P}$ & $\mathbf{S i}$ \\
\hline 28 & Anillo & Los Amarillos & $303 \mathrm{E}$ & $731 / 1$ & ++ & + & & & & & & & & & & & \\
\hline 31 & Campana & Los Amarillos & 301 & $560 / 17$ & ++ & + & & & & & & & & & & & \\
\hline 33 & Cincel & Los Amarillos & $1 \mathrm{~b}$ & $295 / 1$ & ++ & + & & & & - & - & & - & - & & & - \\
\hline 36 & Gota & Los Amarillos & 1 & $12 / 0$ & ++ & + & & & & - & - & & & & & & \\
\hline 37 & Gota & Los Amarillos & 22 & $394 / 1$ & ++ & + & & & & & - & & & & & & \\
\hline 40 & Gota & Los Amarillos & 6 & $97 / 12 a$ & ++ & + & & & & & - & & & - & & & - \\
\hline 48 & No identificado & Los Amarillos & $1 \mathrm{~b}$ & $289 / 1$ & ++ & + & & & & - & - & & & - & & & - \\
\hline 49 & No identificado & Los Amarillos & 16 & $426 / 0$ & ++ & + & & & & & - & & & - & & & - \\
\hline 50 & No identificado & Los Amarillos & 2 & $115 / 1$ & ++ & + & & & & - & - & & & - & & & - \\
\hline 51 & No identificado & Los Amarillos & 302 & $703 / 3 a$ & ++ & + & & & & & - & & & - & & & \\
\hline 52 & No identificado & Los Amarillos & 302 & $703 / 3 b$ & ++ & + & & & & & - & & & - & & & \\
\hline 53 & No identificado & Los Amarillos & 7 & $205 / 2$ & ++ & + & & & & & - & & & - & & & - \\
\hline 54 & No identificado & Los Amarillos & 21 & $502 / 0$ & ++ & + & & & & & & & & & & & \\
\hline 55 & Punzón & Los Amarillos & 20 & $207 / 3$ & ++ & + & & & - & - & & & & - & & & \\
\hline 56 & Punzón & Los Amarillos & 302 & $704 / 15$ & ++ & + & & & & & - & & & - & & & - \\
\hline 57 & Punzón & Los Amarillos & 304 & $745 / 1$ & ++ & + & & & & & & & & & & & \\
\hline 58 & Tumi & Los Amarillos & 9 & $268 / 1$ & ++ & + & & - & & & - & & & - & & & - \\
\hline 59 & Cincel & CAL 20 & B 1 & $10 / 2$ & ++ & + & & - & & & - & & & - & & & - \\
\hline 60 & Tumi & Juella & Superficie & $999 / 0$ & ++ & + & & & & & - & & & - & & - & - \\
\hline 61 & Tumi & Calete & Superficie & $1 / 1$ & ++ & + & & & & & & & & - & & & \\
\hline \multirow[t]{2}{*}{62} & Cincel & Quebrada del & & & & & & & & & & & & & & & \\
\hline & & Cementerio & $4-5$ & $40 / 15$ & ++ & + & - & - & - & - & - & - & - & - & & & - \\
\hline \multirow[t]{2}{*}{63} & Tumi & Quebrada del & & & & & & & & & & & & & & & \\
\hline & & Cementerio & 3 & $55 / 1$ & ++ & + & & & & & & & & & & & \\
\hline 64 & Cincel & Putuquito & Sondeo 2 & $6 / 3$ & ++ & + & & - & & & - & - & - & - & & & - \\
\hline
\end{tabular}

Tabla 11. Piezas integrantes del Subgrupo IIA (++: elemento base, +: elemento secundario, -: trazas).

lograda o bien mezclando cobre líquido con estaño obtenido mediante la fundición de casiterita, un óxido de estaño mucho más abundante en la región analizada, o fundiendo en forma conjunta casiterita con minerales oxidados de cobre (por ejemplo, malaquita, azurita o cuprita). La ausen- 
cia de zinc en los artefactos de este Subgrupo, además, aumenta la probabilidad de que el estaño provenga de casiterita, ya que la estannita normalmente contiene dicho elemento en su composición (Ahfeld y Angelelli 1948).

Para el potasio, magnesio y fósforo caben las mismas consideraciones que para el aluminio, el calcio, el cloro y el silicio: su presencia en la capa de corrosión se explica por el contacto de los objetos con el sedimento que los recubría.

De las piezas que han sido analizadas cuantitativamente (Tabla 12) podemos inferir lo siguiente. El metal de la gota de fundición, que presenta níquel en su composición, probablemente ha sido logrado mezclando cobre líquido obtenido a partir de calcopirita, que suele presentar ese elemento como impureza (Hosler 1994), con estaño obtenido a partir de casiterita, su mineral más abundante en la región de estudio. La fundición de la calcopirita para la obtención del cobre también explicaría la presencia de hierro en tal cantidad.

Los siete objetos restantes no presentan níquel pero sí hierro en su composición. Dos de ellos contienen más de un $0.70 \%$ de este último metal, mientras que en los cinco restantes, en cambio, el hierro no supera el $0.07 \%$. La utilización de cobre obtenido a partir de la fundición de malaquita o azurita podría explicar la presencia de este elemento y la ausencia de níquel en las siete piezas. Sin embargo, si este ha sido el caso, los minerales se han obtenido de por lo menos dos fuentes distintas: una con menas ricas en hierro y otra con menas pobres en este metal. Al igual que en los casos anteriores, el estaño se habría obtenido a partir de casiterita. Esto explicaría la presencia de plomo en los objetos.

En los tres casos en los que el zinc se encuentra en una proporción mayor a $0.80 \%$, existe la posibilidad de que se haya utilizado cobre obtenido a partir de la fundición de crisocola, un mineral abundante en la región y que suele presentar un alto contenido de zinc en su composición (Patterson 1971). En los dos primeros elementos ( $\mathrm{N}^{\mathrm{o}} 7$ y 11), probablemente se lo mezcló con cobre obtenido de malaquita o azurita (lo que explicaría la alta proporción de hierro). En el caso del elemento $\mathrm{N}^{\mathrm{o}} 21$, en cambio, la combinación podría haber sido directamente entre cobre obtenido de crisocola y estaño obtenido de casiterita.
Subgrupo IIB: $\mathrm{Cu}-\mathrm{Sn}-\mathrm{Zn}$. El único integrante de este subgrupo, un cuchillo, está compuesto por una aleación de cobre, estaño y zinc, con hierro y plomo como impurezas (Tabla 13). Al igual que algunos de los objetos del subgrupo anterior, los metales utilizados para su fabricación probablemente fueron obtenidos mediante la fundición de más de un mineral. El cobre puede haber sido obtenido a partir de dos o tres de sus menas: malaquita y/o azurita y crisocola rica en zinc. Esto explicaría la presencia de hierro y zinc en tan alta proporción (Patterson 1971). El estaño, al igual que en los casos anteriores, probablemente proviene de casiterita, lo que daría cuenta de la presencia de plomo en el objeto.

Subgrupo IIC: $\mathrm{Cu}-\mathrm{Sn}-\mathrm{Pb}$. El tumi integrante de este subgrupo está compuesto por una aleación de cobre, estaño y plomo, con una importante cantidad de hierro y zinc como impurezas (Tabla 14). El tipo de composición de este objeto es muy poco común en América por la alta proporción de plomo. No conocemos el mecanismo mediante el cual puede haberse añadido este metal, pero sí que se trata de un agregado intencional, ya que tan alto contenido de plomo no puede deberse a simples impurezas presentes en algún mineral de cobre o estaño (Rovira Lloréns y Gómez Ramos 1995). Podemos explicar tentativamente la composición de este objeto de la siguiente manera: se habrían mezclado cobre obtenido de crisocola y de alguno de sus carbonatos (malaquita y/o azurita), con estaño obtenido de casiterita. A este bronce se le habría añadido luego plomo metálico, quizás obtenido fundiendo galena, un sulfuro muy abundante en la región de estudio.

Subgrupo IID: $\mathrm{Cu}$-Sn-Ni. El Subgrupo IID, al igual que el anterior, está compuesto por un solo objeto, en este caso fabricado con una aleación cobre-estaño-níquel (Tabla 15). El artefacto en cuestión es un badajo. A pesar de que esta aleación es muy poco común en América, en el Noroeste Argentino se han encontrado unos pocos objetos más con esta composición (Ambrossetti 1904). La aleación pudo haberse logrado mezclando cobre obtenido de la fundición de calcopirita (con níquel como impureza) con estaño obtenido de casiterita. Sin embargo, si el níquel está presente en el objeto en cierta cantidad, es más probable que la aleación se haya logrado fundiendo cobre y estaño juntos y agregando algún mineral rico en níquel, como la niquelina (sulfuro escaso, 


\begin{tabular}{|cllccccccccc|}
\hline $\mathbf{N}^{\mathbf{0}}$ & OBJETO & SITIO & CODIGO & $\mathbf{C u}$ & $\mathbf{S n}$ & $\mathbf{P b}$ & $\mathbf{A g}$ & Au & $\mathbf{F e}$ & $\mathbf{Z n}$ & $\mathbf{N i}$ \\
\hline 2 & Cincel & Juella & 36 & 88.80 & 7.60 & tz & nd & - & 0.07 & 0.13 & nd \\
6 & Aguja & Cga. Gde. & 65650 & 85.90 & 6.30 & 0.30 & nd & nd & 0.07 & 0.10 & nd \\
7 & Campanilla & Cga. Gde. & 65606 & 88.10 & 9.75 & 0.37 & nd & nd & 0.71 & 1.10 & nd \\
8 & Cincel & Cga. Gde. & 65608 & 93.65 & 4.70 & 0.10 & nd & nd & 0.97 & nd & nd \\
9 & Cincel & Cga. Gde. & 65660 & 94.25 & 5.28 & 0.05 & nd & nd & 0.07 & nd & nd \\
11 & Gota & Cga. Gde. & 65613 & 89.77 & 4.96 & nd & nd & nd & 0.70 & 0.98 & 0.96 \\
12 & Hachuela & Cga. Gde. & 65607 & 88.10 & 8.40 & 0.20 & nd & nd & 0.02 & nd & nd \\
21 & Tumi & Cga. Gde. & 65610 & 90.40 & 3.90 & 0.10 & nd & nd & 0.07 & 0.84 & nd \\
\hline
\end{tabular}

Tabla 12. Objetos integrantes del Subgrupo IIA. Los valores expresan $\%$ en peso. Referencias: tz: trazas, nd: no detectado, -: no analizado.

\begin{tabular}{|lllllllllllll|}
\hline $\mathbf{N}^{\mathbf{0}}$ & OBJETO & SITIO & CODIGO & $\mathbf{C u}$ & $\mathbf{S n}$ & $\mathbf{P b}$ & $\mathbf{A g}$ & $\mathbf{A u}$ & $\mathbf{F e}$ & $\mathbf{Z n}$ & $\mathbf{N i}$ \\
\hline 10 & Cuchillo & Cga. Gde. & 65611 & 89.30 & 8.20 & 0.10 & nd & nd & 0.40 & 2.10 & nd \\
\hline
\end{tabular}

Tabla 13. Objeto integrante del Subgrupo IIB. Los valores expresan $\%$ en peso.

Referencias: nd: no detectado.

\begin{tabular}{|lcccccccccccc|}
\hline $\mathbf{N}^{\mathbf{0}}$ & OBJETO & SITIO & CODIGO & $\mathbf{C u}$ & $\mathbf{S n}$ & $\mathbf{P b}$ & $\mathbf{A g}$ & $\mathbf{A u}$ & $\mathbf{F e}$ & $\mathbf{Z n}$ & $\mathbf{N i}$ \\
\hline 19 & Tumi & Cga. Gde. & 65603 & 81.25 & 7.67 & 6.05 & nd & nd & 1.39 & 1.77 & nd \\
\hline
\end{tabular}

Tabla 14. Objeto integrante del Subgrupo IIC. Los valores expresan \% en peso.

Referencias: nd: no detectado.

\begin{tabular}{|cccccccc|}
\hline $\mathbf{N}^{\mathbf{0}}$ & OBJETO & SITIO & RECINTO & CODIGO & Cu & Sn & Ni \\
\hline 29 & Badajo & Los Amarillos & 15 & $619 / 1$ & ++ & + \\
\hline
\end{tabular}

Tabla 15. Objeto integrante del Subgrupo IID (++: elemento base, +: elemento secundario).

presente en un solo yacimiento de la provincia de Jujuy).

Subgrupo IIE: $\mathrm{Cu}-\mathrm{Sn}-\mathrm{Ag}$. Los tres integrantes de este subgrupo están compuestos por una aleación de cobre, estaño y plata (Tabla 16). Es difícil explicar con precisión cómo pudo haberse logrado ésta. En la región de estudio existe un mineral de cobre que puede dar cuenta de un contenido de plata tan alto como impureza: la freibergita (Lechtman 1978). O sea, de su fundición podría haberse obtenido cobre y plata en las proporciones presentes en las tres piezas, con hierro y zinc como contaminantes naturales. El estaño y el plomo, por su parte, seguramente se han logrado fundiendo casiterita. Sin embargo, es difícil explicar de esta manera la presencia de níquel en los obje- tos, ya que ni la freibergita ni la casiterita lo presentan en su composición (Hosler 1994).

Lo más probable en este caso es que se haya aleado el cobre con el estaño procediendo de la misma manera que en otros objetos (por ejemplo, el $N^{\circ} 11$ del Subgrupo IIA), y se haya luego añadido plata metálica obtenida de alguno de sus minerales (por ejemplo, galena argentífera, muy abundante en la región, freibergita, o pirargirita).

Lamentablemente, cuando se analizaron estas piezas no se buscaron otros elementos que ahora nos resultarían útiles para inferir los minerales procesados para lograr estas composiciones, como por ejemplo, antimonio y arsénico. 
Subgrupo IIF: $C u-A u$. El único artefacto que compone el Subgrupo IIF, un hacha en miniatura, ha sido elaborada con una aleación de cobre y oro (Tabla 17). También en este caso es importante el resultado de su análisis cuantitativo, ya que la aleación puede ser lograda de dos maneras distintas: fundiendo un mineral de cobre con oro como impureza o, más probablemente en este caso, agregando un metal a otro y fundiéndolos juntos. En el primer caso, la cantidad de oro en el metal resultante es normalmente escasa (Lechtman 1978). Si los análisis cuantitativos confirman que el objeto contiene oro en cierta cantidad (y no sólo trazas), podríamos suponer que el artefacto ha sido elaborado con una aleación lograda mezclando cobre obtenido de alguno de sus minerales con oro nativo, muy común en la Puna jujeña. Si tenemos en cuenta, además, que el EDAX indica que en el objeto hay trazas de azufre, podemos suponer también que el mineral de cobre fundido ha sido algún sulfuro, muy abundantes en la región de estudio.

Subgrupo IIG: $C u-A u-A g$. El último Subgrupo, el IIG, también está integrado por un solo elemento: una gota de fundición (Tabla 18). Los análisis efectuados indican que está compuesta por una aleación de cobre-oro-plata, con estaño y zinc como impurezas. En este caso, consideramos más prudente esperar los resultados de los análisis cuantitativos para inferir la materia prima procesada debido a que las alternativas son numerosas, por ejemplo, mezclar cobre obtenido de calcopirita (con estaño como impureza) con plata (con zinc como impureza) y con oro, o mezclar cobre obtenido de un mineral como enargita (con zinc y plata como impurezas; Hosler 1994) con oro nativo (con estaño como impureza; Patterson 1971), etc. Solamente conociendo las concentraciones de los metales e impurezas podremos avanzar en esta cuestión.

\section{Grupo III}

El Grupo III está compuesto por siete objetos, todos con oro como metal base y plata como elemento secundario. Seis de ellos, en los que no hemos detectado impurezas, constituyen el Subgrupo IIIA. El restante, con hierro y silicio en su estructura, constituye el Subgrupo IIIB.

Subgrupo IIIA: Au-Ag. Todos los objetos de este subgrupo están compuestos por una aleación de base oro, con plata como metal secundario (Tabla 19).
Sin embargo, la proporción de este último elemento no es constante. Uno de los objetos $\left(\mathrm{N}^{\circ} 34\right)$ presenta plata en muy escasa cantidad (menos de $5 \%)$; tres ( $\mathrm{N}^{\mathrm{os}} 35,45$ y 46), contienen aproximadamente entre un 10 y un $20 \%$ de ese metal, mientras que los dos restantes ( $\mathrm{N}^{\text {os }} 43$ y 44) presentan una alta proporción de plata (aproximadamente un $40 \%$ ).

El oro nativo siempre contiene algo de plata, por lo que la cuestión aquí es determinar si la aleación con la que fueron fabricados los objetos es natural o no. Para resolverlo es necesario recurrir a análisis de composición cuantitativos y a estudios metalográficos. De todos modos, en base a los resultados ya obtenidos podemos esbozar lo siguiente. Los objetos que tienen hasta un $20 \%$ de plata en su composición probablemente son el resultado de la utilización de oro nativo para su fabricación. Sin embargo, la procedencia de la materia prima procesada para la fabricación del $\mathrm{N}^{\circ} 34$ (con menos de un 5\% de plata) seguramente no es la misma que la empleada para elaborar los objetos $\mathrm{N}^{\text {os }} 35,45$ y 46 (con un 10 a $20 \%$ de plata).

Los objetos que tienen aproximadamente un $40 \%$ de plata en su estructura, en cambio, serían el producto de una aleación intencional, ya que el oro nativo no contiene plata en tan alta proporción (Tylecote 1970; Patterson 1971; Lechtman 1978). Lo más probable es que se haya mezclado oro fundido con plata obtenida a partir de su estado nativo.

Subgrupo IIIB: Au-Ag-Fe. El único integrante de este subgrupo es una lámina elaborada con una aleación de base oro, con plata como elemento secundario y trazas de hierro y sílice en su estructura (Tabla 20). En este caso, la proporción de plata no supera el $5 \%$. Lo más probable es que el objeto sea el resultado del martillado de una o más "pepitas". Estas

"are probably formed by the welding of grains released by the weathering of rocks. Impact by waterborne pebbles would provide the forces for welding, and the nuggets were then built up by an accretion process trapping clay and quartz in the process" (Tylecote 1970: 22).

Si la pepita es simplemente martillada, contendrá cuarzo (silicio), arcillas y/u óxidos de hierro. En cambio, si es fundida, dichas inclusiones 


\begin{tabular}{|lllccccccccc|}
\hline $\mathbf{N}^{\mathbf{0}}$ & OBJETO & SITIO & CODIGO & $\mathbf{C u}$ & Sn & Pb & Ag & Au & Fe & Zn & Ni \\
\hline 1 & Cincel & Huella & 32 & 84.60 & 10.40 & 0.24 & 4.00 & - & 0.10 & 0.26 & 0.08 \\
3 & Cuchillo & Huella & 90 & 87.70 & 3.70 & 0.20 & 3.80 & - & 0.13 & 0.25 & 0.20 \\
5 & Punzón & Huella & 51 & 88.80 & 2.60 & nd & 3.73 & - & 0.07 & 0.28 & 0.18 \\
\hline
\end{tabular}

Tabla 16. Objetos integrantes del Subgrupo IIE. Los valores expresan $\%$ en peso. Referencias: nd: no detectado; -: no analizado.

\begin{tabular}{|cccccccccccc|}
\hline $\mathbf{N}^{\mathbf{0}}$ & OBJETO & SITIO & RECINTO & CODIGO & $\mathbf{C u}$ & Au & $\mathbf{S}$ & Al & Ca & Cl & Si \\
\hline 42 & Hacha & Los Amarillos & 7 & $483 / 13 \mathrm{a}$ & ++ & + & - & + & - & - & - \\
\hline
\end{tabular}

Tabla 17. Objeto integrante del Subgrupo IIF (++: elemento base, +: elemento secundario, -: trazas).

\begin{tabular}{|cccccccccccc|}
\hline $\mathbf{N}^{\mathbf{0}}$ & OBJETO & SITIO & RECINTO & CODIGO & $\mathbf{C u}$ & Sn & Au & Ag & Zn & Al \\
\hline 39 & Gota & Los Amarillos & 6 & $101 / 12$ & ++ & - & + & + & - & - \\
\hline
\end{tabular}

Tabla 18. Objeto integrante del Subgrupo IIG (++: elemento base, +: elemento secundario, -: trazas).

\begin{tabular}{|c|c|c|c|c|c|c|}
\hline $\mathbf{N}^{0}$ & OВJETO & SITIO & RECINTO & CODIGO & Au & Ag \\
\hline 34 & Cinta & Los Amarillos & 16 & $353 / 1$ & ++ & + \\
\hline 35 & Cinta & Los Amarillos & 16 & $342 / 1$ & ++ & + \\
\hline 43 & Lámina & Los Amarillos & 5 & $108 / 1 \mathrm{a}$ & ++ & + \\
\hline 44 & Lámina & Los Amarillos & 5 & $108 / 1 b$ & ++ & + \\
\hline 45 & Lámina & Los Amarillos & 21 & $450 / 1$ & ++ & + \\
\hline 46 & Lámina & Los Amarillos & 16 & $386 / 66$ & ++ & + \\
\hline
\end{tabular}

Tabla 19. Objetos integrantes del Subgrupo IIIA (++: elemento base, +: elemento secundario).

\begin{tabular}{|lcccccccc|}
\hline $\mathbf{N}^{\mathbf{0}}$ & OBJETO & SITIO & RECINTO & CODIGO & Au & Ag & Fe & Si \\
\hline 47 & Lámina & Los Amarillos & - & $134 / 5$ & ++ & + & - & - \\
\hline
\end{tabular}

Tabla 20. Objeto integrante del Subgrupo IIIB (++: elemento base, +: elemento secundario, -: trazas).

estarán ausentes (Tylecote 1970). Futuros estudios con Rayos X nos permitirán confirmar o no lo que el EDAX nos indica: la presencia de inclusiones en la lámina.

\section{Grupo IV}

El Grupo IV está compuesto por seis objetos, todos elaborados con aleaciones de base plata. Uno de ellos integra el Subgrupo IVA (aleación plataoro), dos el IVB (plata-cobre), dos el IVC (platacobre-estaño) y uno el IVD (plata-cobre-zinc).
Subgrupo IVA: Ag-Au. El Subgrupo IVA está integrado por un solo objeto: una placa fabricada con una aleación de plata y oro, con cobre además de hierro como impurezas (Tabla 21). Al igual que en el caso de algunas piezas del Subgrupo IIIA, esta composición probablemente fue lograda mezclando oro fundido con plata obtenida a partir de su estado nativo. Esto último explicaría la presencia de cobre y de hierro en tales proporciones (Boman 1992 [1908]; Fester 1962). 
Subgrupo IVB: $\mathrm{Ag}-\mathrm{Cu}$. Las dos piezas integrantes de este subgrupo están compuestas por una aleación de plata y cobre, con estaño como impureza. Una de ellas, la no identificada, presenta además trazas de hierro en su estructura. Con los datos disponibles no podemos precisar los minerales que habrían sido procesados para la fabricación de estos objetos. La fundición de plata nativa podría dar cuenta del cobre y del hierro en tales proporciones, pero, siguiendo a Patterson (1971), no del estaño presente. Por el momento preferimos no aventurar interpretaciones en este caso, hasta que no dispongamos de análisis de minerales de plata de la zona de estudio, o de exámenes más completos de las piezas en cuestión.

Subgrupo IVC: Ag-Cu-Sn. El Subgrupo IVC está integrado por dos láminas fabricadas con una aleación de plata, cobre y estaño, con hierro como impureza (Tabla 23). No hay en la región de estudio un mineral que pueda dar cuenta de las pro- porciones detectadas en estas piezas, de manera que para su fabricación seguramente se han mezclado de manera intencional cobre, estaño y plata. El segundo de estos metales probablemente ha sido obtenido a partir de casiterita, pero para el cobre y la plata no podemos precisar los minerales procesados, ya que las posibilidades son varias: malaquita y/o azurita, calcopirita, plata nativa, galena, freibergita, etc. También en este caso es de lamentar el hecho de que no se hayan analizado otros elementos diagnósticos como el antimonio, el arsénico y el bismuto.

Subgrupo IVD: $\mathrm{Ag}-\mathrm{Cu}-\mathrm{Zn}$. El único objeto integrante de este Subgrupo está compuesto por plata como metal base y cobre, zinc e hierro como elementos minoritarios (Tabla 24). Probablemente ha sido fabricado a partir de metal obtenido de plata nativa, ya que esta suele contener cobre, zinc e hierro en cantidades tales como para dar cuenta de las proporciones detectadas (Boman 1992 [1908]; Fester 1962).

\begin{tabular}{|ccccccccccccc|}
\hline $\mathbf{N}^{\mathbf{0}}$ & OBJETO & SITIO & CODIGO & $\mathbf{C u}$ & Sn & Pb & Ag & Au & Fe & Zn & Ni \\
\hline 18 & Placa & Cga. Gde. & 65604 & 1.04 & nd & nd & 51.05 & 47.22 & 0.67 & nd & nd \\
\hline
\end{tabular}

Tabla 21. Objeto integrante del Subgrupo IVA. Los valores expresan $\%$ en peso. Referencias: nd: no detectado.

\begin{tabular}{|cccccccccccc|}
\hline $\mathbf{N}^{\mathbf{0}}$ & OBJETO & SITIO & CODIGO & $\mathbf{C u}$ & $\mathbf{S n}$ & $\mathbf{P b}$ & $\mathbf{A g}$ & $\mathbf{A u}$ & $\mathbf{F e}$ & $\mathbf{Z n}$ & $\mathbf{N i}$ \\
\hline 16 & No identificado & Cga. Gde. & 65602 & 1.81 & 0.38 & nd & 97.23 & Nd & 0.12 & nd & nd \\
17 & Placa & Cga. Gde. & 65600 & 3.65 & 0.20 & nd & 95.86 & Nd & nd & nd & nd \\
\hline
\end{tabular}

Tabla 22. Objetos integrantes del Subgrupo IVB. Los valores expresan \% en peso. Referencias: nd: no detectado.

\begin{tabular}{|cccccccccccc|}
\hline $\mathbf{N}^{\mathbf{0}}$ & OBJETO & SITIO & CODIGO & $\mathbf{C u}$ & Sn & Pb & Ag & Au & Fe & Zn & Ni \\
\hline 13 & Lámina & Cga. Gde. & 65605 & 6.60 & 5.76 & nd & 84.30 & nd & 0.30 & nd & nd \\
14 & Lámina & Cga. Gde. & 65632 & 9.07 & 10.45 & nd & 76.88 & nd & 0.41 & nd & nd \\
\hline
\end{tabular}

Tabla 23. Objetos integrantes del Subgrupo IIE. Los valores expresan \% en peso. Referencias: nd: no detectado.

\begin{tabular}{|ccccccccccccc|}
\hline $\mathbf{N}^{\mathbf{0}}$ & OBJETO & SITIO & CODIGO & $\mathbf{C u}$ & $\mathbf{S n}$ & $\mathbf{P b}$ & $\mathbf{A g}$ & $\mathbf{A u}$ & $\mathbf{F e}$ & $\mathbf{Z n}$ & $\mathbf{N i}$ \\
\hline 15 & No identificado & Cga. Gde. & 65601 & 4.78 & nd & nd & 90.95 & nd & 1.51 & 2.35 & nd \\
\hline
\end{tabular}

Tabla 24. Objeto integrante del Subgrupo IIE. Los valores expresan $\%$ en peso.

Referencias: nd: no detectado. 
Tendencias temporales

En la Tabla 25 presentamos la distribución temporal tentativa de los objetos analizados, ordenados de acuerdo a los subgrupos de composición. En la Tabla 26 señalamos la distribución temporal tentativa de los Subgrupos de composición.

\section{Consideraciones finales}

Los resultados de los análisis efectuados nos indican que los metales necesarios para la fabricación de los objetos considerados se han obtenido de una amplia variedad de minerales. Nuestros estudios nos sugieren que hay gran probabilidad de que se hayan procesado al menos los especificados en la Tabla 27.

En base a las composiciones de las piezas analizadas, podemos plantear además que existen ciertas posibilidades de que los metalurgos prehispánicos también hayan procesado los minerales presentados en la Tabla 28.

De acuerdo con los datos de los que disponemos, de todos estos minerales sólo tres han sido identi-

\begin{tabular}{|c|c|c|c|c|c|c|c|}
\hline \multirow[t]{2}{*}{ SUBGRUPOS } & \multirow[t]{2}{*}{ CD } & \multicolumn{5}{|c|}{ FASES } & \multirow[t]{2}{*}{ Totales } \\
\hline & & $\overline{\mathrm{CAL}}$ & SAR & PUK & PUK/INKA & INKA & \\
\hline IA & & & & 2 & 1 & & 3 \\
\hline IB & & & & 2 & 1 & & 3 \\
\hline IIA & & 2 & 2 & 12 & 13 & 2 & 31 \\
\hline IIB & & & & & 1 & & 1 \\
\hline IIC & & & & & 1 & & 1 \\
\hline IID & & & & 1 & & & 1 \\
\hline IIE & & & & 3 & & & 3 \\
\hline IIF & & & & & & 1 & 1 \\
\hline IIG & & & & & 1 & & 1 \\
\hline IIIA & & & & 6 & & & 6 \\
\hline IIIB & 1 & & & & & & 1 \\
\hline IVA & & & & & 1 & & 1 \\
\hline IVB & & & & & 2 & & 2 \\
\hline IVC & & & & & 2 & & 2 \\
\hline IVD & & & & & 1 & & 1 \\
\hline Totales & 1 & 2 & 2 & 26 & 24 & 3 & 58 \\
\hline
\end{tabular}

Tabla 25. Distribución temporal tentativa de los elementos metálicos analizados, ordenados de acuerdo a los Subgrupos de composición. CD: cronología desconocida. Fases: CAL: Calete (1100-1280 DC), SAR: Sarahuaico (1280-1350 DC), PUK: Pukara (1350-1430 DC), Inka (1430-1535 DC).

\begin{tabular}{|c|c|c|c|c|c|c|}
\hline \multirow[t]{2}{*}{ SUBGRUPOS } & \multirow[t]{2}{*}{ CD } & \multicolumn{5}{|c|}{ FASES } \\
\hline & & $\overline{\mathrm{CAL}}$ & SAR & PUK & PUK/INKA & $\overline{\text { INKA }}$ \\
\hline IA & & & & - & - & \\
\hline IB & & & & - & - & \\
\hline IIA & & - & - & - & - & - \\
\hline IIB & & & & & - & \\
\hline IIC & & & & & - & \\
\hline IID & & & & - & & \\
\hline IIE & & & & - & & \\
\hline IIF & & & & & & - \\
\hline IIG & & & & & - & \\
\hline IIIA & & & & - & & \\
\hline IIIB & $\mathrm{x}$ & & & & & \\
\hline IVA & & & & & - & \\
\hline IVB & & & & & - & \\
\hline IBC & & & & & - & \\
\hline IBD & & & & & - & \\
\hline
\end{tabular}

Tabla 26. Distribución temporal tentativa de los Subgrupos de composición. CD: cronología desconocida. Fases: CAL: Calete (11001280 DC), SAR: Sarahuaico (1280-1350 DC), PUK: Pukara (1350-1430 DC), Inka (1430-1535 DC). 


\begin{tabular}{|llcl|}
\hline COBRE & ESTAÑO & ORO & PLATA \\
\hline Cobre nativo & Casiterita & Oro nativo & Plata nativa \\
Malaquita & & & \\
Azurita & & & \\
Crisocola & & & \\
Cuprita & & & \\
Calcopirita & & & \\
\hline
\end{tabular}

Tabla 27. Minerales probablemente utilizados para la obtención de los metales señalados.

\begin{tabular}{|cccc|}
\hline ESTAÑO & PLATA & PLOMO & NIQUEL \\
\hline Estannita & $\begin{array}{c}\text { Freibergita } \\
\text { Galena }\end{array}$ & Galena & Niquelina \\
\hline
\end{tabular}

Tabla 28. Minerales posiblemente utilizados para la obtención de los metales señalados.

ficados en yacimientos ubicados en la propia quebrada de Humahuaca; los tres son menas de cobre: malaquita, azurita y calcopirita. Los dos primeros han sido localizados en numerosos bolsones distribuidos a lo largo de toda la quebrada, pero son especialmente frecuentes frente a las localidades de Humahuaca, Huacalera, Tilcara, Maimará y Purmamarca. La calcopirita, el tercer mineral, ha sido identificada en vetas distribuidas por diversos sectores de la quebrada, aunque en cantidades mucho menores que la malaquita y la azurita. Sin embargo, ninguno de los tres minerales referidos es exclusivo de Humahuaca. Por el contrario, todos son abundantes también en el resto de la provincia de Jujuy, de manera que debemos considerar que son los únicos que pudieron haber sido explotados en la propia quebrada, pero también pudieron haber sido recolectados en yacimientos ubicados en otros ambientes, cercanos o alejados: puna, cordillera oriental, valles y sierras subandinas.

A pesar de que el cobre nativo no ha sido reportado en la quebrada de Humahuaca, dadas sus características metalogénicas no debemos descartar la posibilidad de que haya existido, o de que aún exista, en ciertos bolsones cupríferos de la zona. Esto se debe a que es un mineral que suele originarse en las zonas de meteorización de los yacimientos que presentan óxidos y carbonatos de cobre, sumamente abundantes en la región. De todos modos, en tales lugares siempre es esperable encontrarlo en muy escasa cantidad.
Otros de los minerales probablemente utilizados en tiempos prehispánicos no han sido detectados en la quebrada de Humahuaca, pero pudieron haber sido explotados en yacimientos relativamente cercanos, localizados a una distancia de entre 40 y $80 \mathrm{~km}$ en línea recta desde Los Amarillos. Es el caso del cobre nativo (detectado en Chorrillos), la cuprita (en la quebrada de Huachichocana y Chorrillos), la crisocola (en la quebrada de Huachichocana, Santa Ana, San Rafael y Chorrillos), la freibergita (en Sierra de Aguilar) y la galena (en Cerro Chañi, Sierra de Aguilar, Palca de Aparzo, Gigante y La Italiana). También ha sido reportado el hallazgo de oro nativo en yacimientos ubicados aproximadamente a la distancia señalada (en Sierra de Aguilar, Purísima y Chorrillos). Sin embargo, en tales sitios se lo encuentra en muy escasa cantidad, localizándose sus principales yacimientos en el ámbito puneño, a más de $120 \mathrm{~km}$ de distancia en línea recta de Los Amarillos.

Algunos de los minerales especificados en las Tablas 27 y 28 son abundantes en la región de estudio, pero en lugares sumamente alejados de los sitios arqueológicos considerados. Como ya lo señalamos, uno de estos minerales es el oro nativo, cuyas vetas y concentraciones aluvionales se encuentran prácticamente confinadas a la puna. Otro ejemplo es la casiterita, el mineral de estaño más importante de la provincia de Jujuy, ampliamente utilizado en tiempos prehispánicos para la fabricación de bronce. Sus yacimientos están localizados exclusivamente en el sector más occidental de la Puna jujeña, a más de 120 km lineales de Los Amarillos.

Por último, existen tres minerales que, a diferencia de los anteriores, han sido detectados sólo en algunos pocos lugares. Uno de ellos, a juzgar por los resultados de nuestros estudios, ha sido utilizado por los antiguos metalurgos: la plata nativa. Para los dos restantes (estannita y niquelina), los datos aún no son definitivos: existen ciertas posibilidades de que también hayan sido explotados, pero aún no podemos asegurarlo. La plata nativa sólo ha sido reportada en dos yacimientos de la Puna jujeña: Pircas (a unos $140 \mathrm{~km}$ en línea recta de Los Amarillos), y La Providencia (a unos 150 $\mathrm{km})$. La estannita, por su parte, ha sido identificada en Pirquitas-San Marcos, Pan de Azúcar, La Providencia y El Quevar, siendo los dos primeros yacimientos los más cercanos a Los Amarillos 
(110 y $140 \mathrm{~km}$ en línea recta, respectivamente). La niquelina, finalmente, sólo ha sido localizada en Purísima, ubicada a unos $35 \mathrm{~km}$ del asentamiento mencionado (Angelelli et al. 1983).

En definitiva, de los cuatro metales básicos de la muestra analizada, el cobre, el más utilizado por los antiguos metalurgos, pudo haber sido extraído de la misma quebrada o de áreas aledañas. Pero como ya lo señalamos, también pudo haber sido explotado en los yacimientos ubicados en otros ambientes de la región de estudio (puna, cordillera oriental, valles y sierras subandinas). La distribución de sus minerales, entonces, es tan amplia que no nos permite por el momento efectuar inferencias más precisas sobre sus posibles procedencias.

Los minerales de estaño y oro, en cambio, presentan una distribución tal que podemos plantear que las tareas para su obtención debieron efectuarse lejos de Humahuaca. Más allá de algunos yacimientos aislados importantes localizados en el sector más occidental de la provincia de Jujuy, a lo largo de su límite con Chile, tanto el oro como la casiterita se encuentran en abundancia en depósitos aluviales del sector central de la Puna jujeña, al sudoeste de la localidad de Rinconada. El oro, además, es frecuente en un área amplia del extremo norte de Jujuy, en las cercanías de la localidad de Santa Catalina. Basándonos en la distribución de estos minerales, podemos plantear entonces que su explotación debió llevarse a cabo exclusivamente (en el caso de la casiterita) y casi exclusivamente (en el caso del oro) en las zonas mencionadas.

La plata nativa, por último, sólo ha sido identificada en dos yacimientos localizados en el sector occidental de Jujuy. Ambos depósitos (Pircas y La Providencia) son polimetálicos, con minerales de plata, cobre, estaño y oro. Si bien debemos tener presente la posibilidad de que, dadas sus características metalogénicas, haya existido también plata nativa en muy escasa cantidad en otros depósitos argentíferos de la región (como Sierra de Aguilar), por el momento sólo podemos postular que su explotación debió realizarse probablemente en los dos yacimientos mencionados.

El aprovechamiento de tal variedad de minerales implicaba, por parte de los antiguos metalurgos, el dominio de técnicas de extracción diversas y diferentes entre sí, cada una con requerimientos de instrumental específico: lavado de sedimentos para la obtención de oro y casiterita, explotación de vetas para el aprovisionamiento de calcopirita, y de lentes o bolsones para ciertos minerales secundarios de cobre (malaquita, azurita, cuprita). También requería del conocimiento de distintas técnicas de fundición de minerales. La mayoría de ellos podían fundirse de manera relativamente sencilla, pero para obtener cobre a partir de sulfuros el proceso es mucho más complejo, ya que es necesario efectuar primero una tostación del mineral para eliminar el azufre presente. Recién después puede procederse a su fundición. Este aspecto de la producción metalúrgica en la región es una muestra más del notable nivel alcanzado en el dominio de esta tecnología por las sociedades prehispánicas del Noroeste Argentino.

El estudio presentado en este trabajo deberá completarse con nuevos análisis. Sin embargo, la información generada hasta el momento permitirá diseñar estrategias para la detección de evidencias de explotación minera, rutas de tráfico de minerales y localización de lugares de procesamiento de las materias prima.

Agradecimientos Quiero agradecer especialmente a Axel Nielsen por haberme permitido trabajar con los materiales recuperados por su equipo, y por su guía en esta investigación. También a Luis González, Tulio Palacios y Edgardo Cabanillas por su ayuda en cuestiones metalúrgicas, y a Raúl Zelaya y Josefina Angiorama por la confección de los dibujos de las piezas analizadas. Este trabajo ha sido posible gracias a Becas otorgadas por el CONICET y la Fundación OSDIC. Las interpretaciones vertidas en este artículo son de mi exclusiva responsabilidad. 


\section{REFERENCIAS CITADAS}

AHFELD, F., 1948. La terminación meridional de la faja estannífera boliviana. Revista de la Asociación Geológica Argentina 3 (2): 133-144.

AHFELD, F. y V. ANGELELLI, 1948. Las especies minerales de la República Argentina. Instituto de Geología y Minería, Universidad Nacional de Tucumán, San Salvador de Jujuy.

AMBROSETTI, J., 1904. El bronce en la Región Calchaquí. Anales del Museo Nacional de Buenos Aires 11: 163-314.

ANGELELLI, V., 1984. Yacimientos metalíferos de la República Argentina. Vol. I y II. Comisión de Investigaciones Científicas de la Provincia de Buenos Aires. Instituto de Geología Aplicada, Facultad de Ciencias Naturales y Museo, Universidad Nacional de La Plata, La Plata.

ANGELELLI, V., M. K. de BRODTKORB, C. GORDILLO y H. GAY, 1983. Las especies minerales de la República Argentina. Servicio Minero Nacional, Buenos Aires.

ANGIORAMA, C., 1999. La metalurgia prehispánica en la quebrada de Humahuaca (Provincia de Jujuy, Argentina). Tesis de Maestría inédita, Universidad Internacional de Andalucía, La Rábida.

_2001 Ms. Objetos metálicos, yacimientos minerales y antiguos metalurgos. Aspectos de la metalurgia prehispánica en la quebrada de Humahuaca (Jujuy, Argentina).

BOMAN, E., 1992 [1908]. Antigüedades de la Región Andina de la República Argentina y del Desierto de Atacama. 2 vols. Universidad Nacional de Jujuy, San Salvador de Jujuy.

BROWMAN, D., 1984. Prehispanic aymara expansion. The Southern Altiplano and San Pedro de Atacama. Estudios Atacameños 7: 236-252.

CIGLIANO, E., 1967. Investigaciones antropológicas en el yacimiento de Juella (Depto. de Tilcara, Provincia de Jujuy). Revista del Museo de La Plata VI: 123-249.

COIRA, B., 1979. Descripción geológica de la Hoja 3c, Abra Pampa, Provincia de Jujuy. Boletín 170. Servicio Geológico Nacional.

FESTER, G., 1962. Copper and copper alloys in ancient Argentina. Chymia: Annual Studies in the History of Chemistry 8: 21-31. University of Pennsylvania Press, Philadelphia.

GONZALEZ, L., 1992. Mina que fue en otros tiempos... Un acercamiento a la minería prehispánica. Revista de Antropología 11: 20-30.

HOSKOLD, H., 1889. Memoria general y especial sobre las minas, metalurgia, leyes de minas, recursos, ventajas, etc. de la explotación de minas en la República Argentina.
Imprenta y estereotipia del "Courrier de La Plata", Buenos Aires.

HOSLER, D., 1994. The sounds and colors of power. The Massachusetts Institute of Technology Press, Cambridge.

LECHTMAN, H., 1978. Temas de metalurgia andina. En Tecnología Andina, R. Ravines (Comp.), pp. 489-520. Instituto de Estudios Peruanos, Instituto de Investigación Tecnológica, Industrial y de Normas Técnicas, Lima.

MADDIN, R., T. WHEELER y J. MUHLY, 1980. Distinguishing artifacts made of native copper. Journal of Archaeological Science 7: 211-225.

NIELSEN, A. 1997. Tiempo y cultura material en la quebrada de Humahuaca, 700-1650 DC. Instituto Interdisciplinario Tilcara, Facultad de Filosofía y Letras, Universidad de Buenos Aires, San Salvador de Jujuy.

-1998. Tendencias de larga duración en la ocupación humana del altiplano de Lípez (Potosí, Bolivia). En Las sociedades locales y sus territorios, B. Cremonte (Comp.), pp. 65-102. Universidad Nacional de Jujuy, San Salvador de Jujuy.

— 1999. El tráfico caravanero visto desde la Jara. Estudios Atacameños 14: 339-371.

-2000. Andean caravans: An ethnoarchaeology. Ph. D. Dissertation, University of Arizona, Tucson.

-2001. Bienes de prestigio en perspectiva histórica: El caso del tráfico de malaquita circumpuneño. Actas del XIV Congreso Nacional de Arqueología Argentina (Resúmenes), p. 262. Universidad Nacional de Rosario, Rosario.

NUÑEZ, L., 1987. Tráfico de metales en el Area Centro-Sur Andina: Factos y expectativas. Cuadernos del Instituto Nacional de Antropología 12: 73-105.

NUÑEZ, L. y T. DILLEHAY, 1995. Movilidad giratoria, armonía social y desarrollo en los Andes Meridionales: Patrones de tráfico e interacción económica. Universidad Católica del Norte, Antofagasta (Segunda edición).

PATTERSON, C., 1971. Native copper, silver, and gold accessible to early metallurgists. American Antiquity 36 (3): $286-321$

PERNICKA, E., F. BEGEMANN, S. SCHMITT-STRECKER, H. TODOROVA e I. KULEFF, 1997. Prehistoric copper in Bulgaria. Its composition and provenance. Eurasia Antiqua. Zeitschrift für Archäologie Eurasiens 3: 41-180, Institut Mainz am Rhein.

PETERSEN, G., 1970. Minería y metalurgia en el Antiguo Perú. Arqueológicas 12, Lima.

ROVIRA LLORENS, S. y P. GOMEZ RAMOS, 1995. Los objetos de metal de la colección Juan Larrea: Un estu- 
dio arqueometalúrgico. Anales del Museo de América 3: 21-33.

ROVIRA LLORENS, S., P. GOMEZ RAMOS e I. MONTERO RUIZ, 1998 Aspectos metalúrgicos del poblado del Bronce Final de Genó (Aitona, Lleida). En Genó: Un poblado del Bronce Final en el Bajo Segre (Lleida), J. Maya, F. Cuesta y J. López Cachero (Eds.), pp. 225-238. Publicacions de la Universitat de Barcelona, Barcelona.

SALAS, M., 1945. El antigal de Ciénaga Grande (quebrada de Purmamarca, Provincia. de Jujuy). Publicaciones del Museo Etnográfico, Serie A, V, Facultad de Filosofía y Letras, Universidad de Buenos Aires, Buenos Aires.

SGROSSO, P., 1943. Contribución al conocimiento de la minería y geología del Noroeste Argentino. Boletín 53, Dirección de Minas y Geología, Buenos Aires.

SUBSECRETARIA DE MINERIA (SSM), 1973. Provincias de Salta y Jujuy. Mapa minero. Escala 1:750000. Buenos Aires.

TARRAGO, M., 1977. Relaciones prehispánicas entre San Pedro de Atacama (norte de Chile) y regiones aledañas: La quebrada de Humahuaca. Estudios Atacameños 5: 50-63.
TARRAGO, M. y L. GONZALEZ, 1998. La producción metalúrgica prehispánica en el asentamiento de Tilcara (Prov. de Jujuy). Estudios preliminares sobre nuevas evidencias. En Las sociedades locales y sus territorios, B. Cremonte (Comp.), pp. 179-198. Universidad Nacional de Jujuy, San Salvador de Jujuy.

TURNER, J., 1978. Descripción geológica de las Hojas 1a y b, Santa Catalina, y 2a, San Juan de Oro, Provincia de Jujuy. Boletín 156-157, Servicio Geológico Nacional, Buenos Aires.

_ - 1982. Descripción geológica de la Hoja 3ab, Mina Pirquitas, Provincia de Jujuy. Boletín 187, Servicio Geológico Nacional, Buenos Aires.

TYLECOTE, R., 1970. The composition of metal artifacts: A guide to provenance? Antiquity XLIV: 19-25.

VILELA, C. 1969. Descripción geológica de la Hoja 6C, San Antonio de los Cobres, Provincias de Salta y Jujuy. Boletín 110, Dirección Nacional de Geología y Minería, Buenos Aires. 